\title{
National-Scale Variation and Propagation Characteristics of Meteorological, Agricultural, and Hydrological Droughts in China
}

\author{
Ning Yao ${ }^{1}\left(\mathbb{D}\right.$, Huichao Zhao ${ }^{1,2}$, Yi Li ${ }^{1,3, *}$, Asim Biswas ${ }^{4} \mathbb{C}^{\text {, Hao Feng }}{ }^{5}$, Fenggui Liu ${ }^{6}$ and \\ Bakhtiyor Pulatov ${ }^{7}$ \\ 1 College of Water Resources and Architecture Engineering, Northwest A\&F University, \\ Yangling 712100, China; yaoning@nwafu.edu.cn (N.Y.); zhaohuichao@nwafu.edu.cn (H.Z.) \\ 2 Henan Provincial Institute of Communications Planning Survey \& Design, Zhengzhou 450000, China \\ 3 Key Lab of Agricultural Water and Soil Engineering of Education Ministry, Northwest Agriculture and \\ Forestry University, Yangling 712100, China \\ 4 School of Environmental Sciences, University of Guelph, Guelph, ON N1G 2W1, Canada; \\ biswas@uoguelph.ca \\ 5 Institute of Water and Soil Conservation, Chinese Academy of Sciences and Ministry of Water Resources, \\ Yangling 712100, China; nercwsi@ms.iswc.ac.cn \\ 6 Academy of Plateau Science and Sustainability, Qinghai Normal University, Xining 810016, China; \\ lfg@qhnu.edu.cn \\ 7 Tashkent Institute of Irrigation and Agricultural Mechanization Engineers, Qoriy Niyoziy 39, \\ Tashkent 100000, Uzbekistan; bakhtiyor.pulatoff@gmail.com \\ * Correspondence: liyi@nwafu.edu.cn
}

Received: 13 September 2020; Accepted: 12 October 2020; Published: 16 October 2020

\begin{abstract}
The regional and national scales variation and propagation characteristics of different types of droughts are critical for improving drought resilience, while information is limited in China. The objective of this research was to investigate the evolution and propagation characteristics of three types of droughts using standardized indices at multi-timescales in different sub-regions of China. The indices included Standardized Precipitation/Soil Moisture/Runoff Index (SPI/SSI/SRI) using the optimal probability density function, representing meteorological, agricultural, and hydrological droughts based on precipitation, soil water storage, and baseflow-groundwater runoff, respectively. Wavelet analysis was used to reveal their periodical characteristics. Modified Mann-Kendall trend test was used to compare the trend among drought indices. Correlation coefficients between SPI and SSI/SRI were calculated to identify the time-lags of SPI with SSI and SRI. In general, droughts indicated by SPI agreed well with the historical drought events at different sub-regions. The main periods of SSI were closer to SPI than SRI, indicating stronger connections of agricultural drought with meteorological drought. A weaker connection between meteorological and agricultural/hydrological droughts at shorter timescales was observed in northwestern arid and semi-arid regions. The propagation from meteorological to agricultural or hydrological droughts were well denoted by the lagged time (months) from SPI to SSI or SRI at a timescale ranged from 0 (mostly located in south China) to 5 months (mostly located in northeastern China) for 1-, 3-, 6-, 12-, or 24-month timescale; this was a new finding for China. The methods of wavelet combining trend test and Pearson coefficient showed meaningful power for revealing the drought propagation characteristics and the obtained results can be a good reference for other regions of the world since this study compared different climate zones from arid to humid conditions. The study provides crucial information and guidance to develop drought management strategies at regional to national scale and their critical time of action.
\end{abstract}

Keywords: drought type; standardized drought index; wavelet analysis; trend; lag 


\section{Introduction}

Drought, a globally common natural hazard and one of the most damaging environmental disasters resulting from climate variations, has threatened human life, property safety, and ecosystem at large [1-3]. For example, drought impedes the growth and development of crops and reduces crop yields. Similarly, severe drought may cause short or long-term water crisis and affect human society safety and security. Against the background of global warming, severe drought events have occurred throughout China, the damages through crop yield reduction, economic loss, safety of our society and others caused by drought cannot be neglected [4]. Therefore, it is important to quantify the problematic influence of drought hazard in China.

There are several types of droughts depending on the water deficit patterns including meteorological, agricultural, hydrological, and socio-economic [5]. Meteorological drought refers to a lack of precipitation over a region for a period of time [6]. The most obvious manifestation is the continuous below normal rainfall over a certain period. Agricultural drought refers to soil moisture that cannot meet the water demand of plants at different growth stages [7]. Hydrological drought refers to a period with inadequate surface and subsurface water resources for established water uses of a given water resources management system [6]. Socio-economic drought is associated with failure of water resources systems to meet water demands and thus associating droughts with supply of and demand for an economic good (water) [6]. Continuation of meteorological to agricultural or hydrological drought involves a suite of processes including occurrence, development, and propagation.

In view of the definition of water cycle and drought, when precipitation is lower than normal value, it will cause meteorological drought, while the occurrence of agricultural or hydrological drought is not only related to precipitation reduction but also affected by land surface evaporation and other factors. Thus, the occurrence of agricultural and hydrological drought can be regarded as the inheritance and development of meteorological drought, and there is time lag between meteorological, agricultural, and hydrological droughts [8-10]. Considering multi-timescales, it is important to understand the relationship between the three drought types for investigating the process of drought transmission.

Although there were some previous studies which compared different types of drought [11,12], information on the propagation characteristics among different types of droughts are scarce $[10,13]$. Drought indicators are commonly used to identify the occurrence of a current drought event and its severity. These can also be used to assess past events and forecast future events. To date, more than 150 drought indicators are proposed or developed to characterize a specific degree of wetness and dryness [14]. Recently, the drought characteristics were investigated by using some remote sensing (RS) based indicators. For example, Gidey et al. [15] compared RS-based agricultural drought indicators of Vegetation Health Index (VHI), Normalized Difference Water Index (NDWI), and Normalized Difference Vegetation Index (NDVI) with Standardized Precipitation Index (SPI). They reported a significant and positive correlation between VHI and SPI at the three-month timescale. Ezzine et al. [16] proposed the Standardized Water Index (SWI) based on Normalized Difference Water Index (NDWI) and compared with the SPI based on meteorological drought and the Standardized Vegetation Index (SVI) based on Normalized NDVI. They also tested the consistency of the three drought indexes under different land use types during a period of 15 years (1998-2012) and reported a stronger agreement between SVI and SPI in autumn and winter than that between SPI and SWI. A satisfactory correlation between SWI and SPI was also reported [16]. Li et al. [11] analyzed and compared the meteorological and agricultural drought characteristics in Qinghai-Tibet Plateau by calculating Standardized Precipitation Evapotranspiration Index (SPEI) and Temperature Vegetation Dryness Index (TVDI) with the dry area data from 2001 to 2014 [17]. They reported a deterioration of drought situation in Qinghai-Tibet Plateau from 1971 to 2014, and an improved performance of SPEI over TVDI.

To study the propagation processes, Huang et al. [10] studied the transmission time from meteorological to hydrological drought and the influencing factors in Weihe River Basin using SPI and Soil Runoff Index (SRI) as the meteorological and hydrological drought indicators, respectively. They observed that the propagation time was affected by seasons and had a strong relationship with 
atmospheric circulation factors (such as El Niño Southern Oscillation and Arctic Oscillation) and underlying surface conditions. Wu et al. [18] used SPI and SRI and reported that the average duration and severity of hydrological drought in the Loess Plateau was greater than that of meteorological drought. They found that the maximum duration of hydrological drought was five days in the Loess Plateau. Hisdal et al. $[19,20]$ used empirical orthogonal function, Monte Carlo simulation, and probability and reported that the frequency and duration of meteorological drought showed opposite relationship with hydrological drought. Similarly, Wu et al. [13] established a non-linear relationship between meteorological and hydrological drought for intensity and duration using a binary relationship model. They observed that the operation of the reservoir shortened the transmission process.

Several studies investigated the variation features of meteorological, agricultural, and hydrological droughts. For example, Wang et al. [21] explored the effects of climate change on the duration, intensity, and frequency of meteorological, agricultural, and hydrological droughts over 1991-2000 and 2091-2100 using Global Climate Models' emission scenarios. Duan et al. [22] analyzed the impacts of climate change on meteorological, agricultural, and hydrological droughts in the future. Both studies pointed out that even if the characteristics of meteorological drought were stable, the future climate change would have greater impacts on agricultural and hydrological droughts. Wu et al. [13] developed a relational model between meteorological and hydrological drought duration and intensity. Drought characteristics at different timescales also differed. For example, Vicente-Serrano et al. [23] used different scales of SPI and analyzed the differences of the patterns of drought in the Iberian Peninsula. Pasho et al. [24] and Xu et al. [25] reported variable influences of different timescales of droughts on plant growth. The possible connections between the timescales of meteorological and agricultural (or hydrologic) drought are crucial. We can also further improve our understanding of the propagation characteristics of drought using lag time by analyzing and comparing the drought characteristics of different drought types. However, there is no information on the spatial distribution of meteorological, agricultural, or hydrological droughts and their interrelations at different timescales across China. Additionally, most previous research has focused on describing the characteristics of single drought type. The comparative studies of different drought types and their connections are limited since it required much more data, more indices, and more complicated methods.

The long-term goal of this work was to simultaneously investigate three types of droughts and reveal the drought propagation features across China. The specific objectives were to: (i) characterize spatiotemporal variations of precipitation (PPT), soil water storage (SWS), and baseflow-groundwater runoff (BGR) and their dominant scale of occurrence; (ii) compute multi-timescale SPI, standardized soil moisture index (SSI), and SRI based on PPT, SWS, and BGR data and analyze characteristics of three types of droughts; and (iii) identify mutual relationships and propagation features among different types of droughts at different timescales. The study was carried out at seven climatic regions covering mainland China and aimed at generating information to support policy development in managing and coping with drought hazards.

\section{Materials and Methods}

\subsection{Regional Setting}

China is in the southeastern region of the Eurasian plate with an area of $9.634057 \times 10^{6} \mathrm{~km}^{2}$. The topography is lower in the east and higher in the central and south-west area, with a three-staircase-terrain. The highest region is Qinghai-Tibetan Plateau, located in southwestern China. The Bohai, Yellow, and South China seas surround the southeast regions. The annual precipitation gradually increases from the northwest inland to the southeast coastal areas [26]. The climate is mainly influenced by the summer monsoon. In addition, precipitation and high temperature events are concentrated in summer and autumn, with relatively less precipitation in winter and spring. The temperature in the south is higher than the north, and the north is near the source of the winter wind. The isotherm of $0{ }^{\circ} \mathrm{C}$ in January passes through the Qinling Mountains-Huaihe line in China. 
The distinctive location and multiple combinations of different climatic variables (temperature, wind speed, precipitation, humidity, radiation, etc.) make China a unique place between dry and humid regions. According to the climatic and geographical features, China is divided into seven climatic sub-regions [27] (Figure 1). For further details on the general climatic features of different sub-regions, we refer readers to Yao et al. [26]. However, it should be noted that the region-partitioning order in this study is different than the one proposed by Yao et al. [26]. The region-partitioning order was based on an increasing PPT (the least PPT for the sub-region 1).

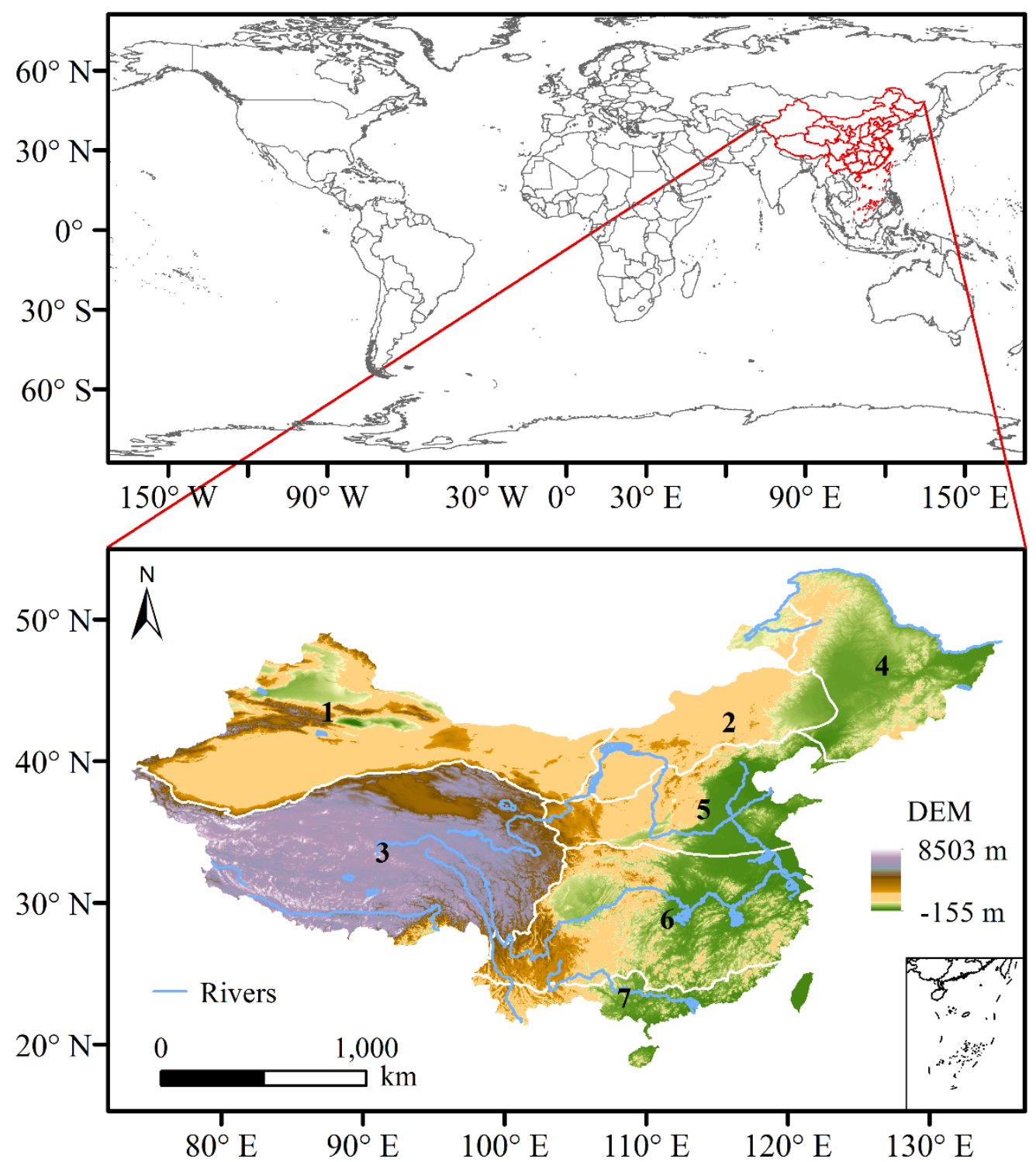

Figure 1. Map of elevation and climatic sub-regions in China. The white lines are boundaries of neighboring sub-regions. The Arabic numerals denote different sub-regions.

\subsection{Datasets}

Before studying drought, the changes in precipitation, soil moisture, and runoff over time and space should be investigated. The global land data assimilation system (GLDAS) contains global data $\left(2.5^{\circ}\right.$ to $\left.1 \mathrm{~km}\right)$ with good accuracy and applicability $[28,29]$, produced from advanced land assimilation technologies, models, and observation data from remote sensing satellites. Compared with the famine early warning systems network (FEWS NET) land data assimilation system, GLDAS driver data were more accurate and simulation results were more reasonable [30]. At present, GLDAS supports a lot 
of research work with its unique advantages including large spatial coverage at high resolution over 1948-2010 [31-34]. However, due to the limitation of the observed data, the observed precipitation data and the data from GLDAS were compared and verified in this study and presented in Figure 2 (the number in the upper left corner represents the region, and the number in the lower right corner represents the site number of the region), to characterize the good reliability and accuracy of the GLDAS dataset. The GLDAS data included PPT, and SWS within 0-200 cm. The BGR data were obtained from Google Earth Engine [35]. The spatial resolution of the datasets is $0.25^{\circ}$, and the time range is from 1 January, 1948 to 31 December 2010. The raster data were extracted at corresponding grid cells using spatial data extraction method (extracting value to point) in ArcGIS.
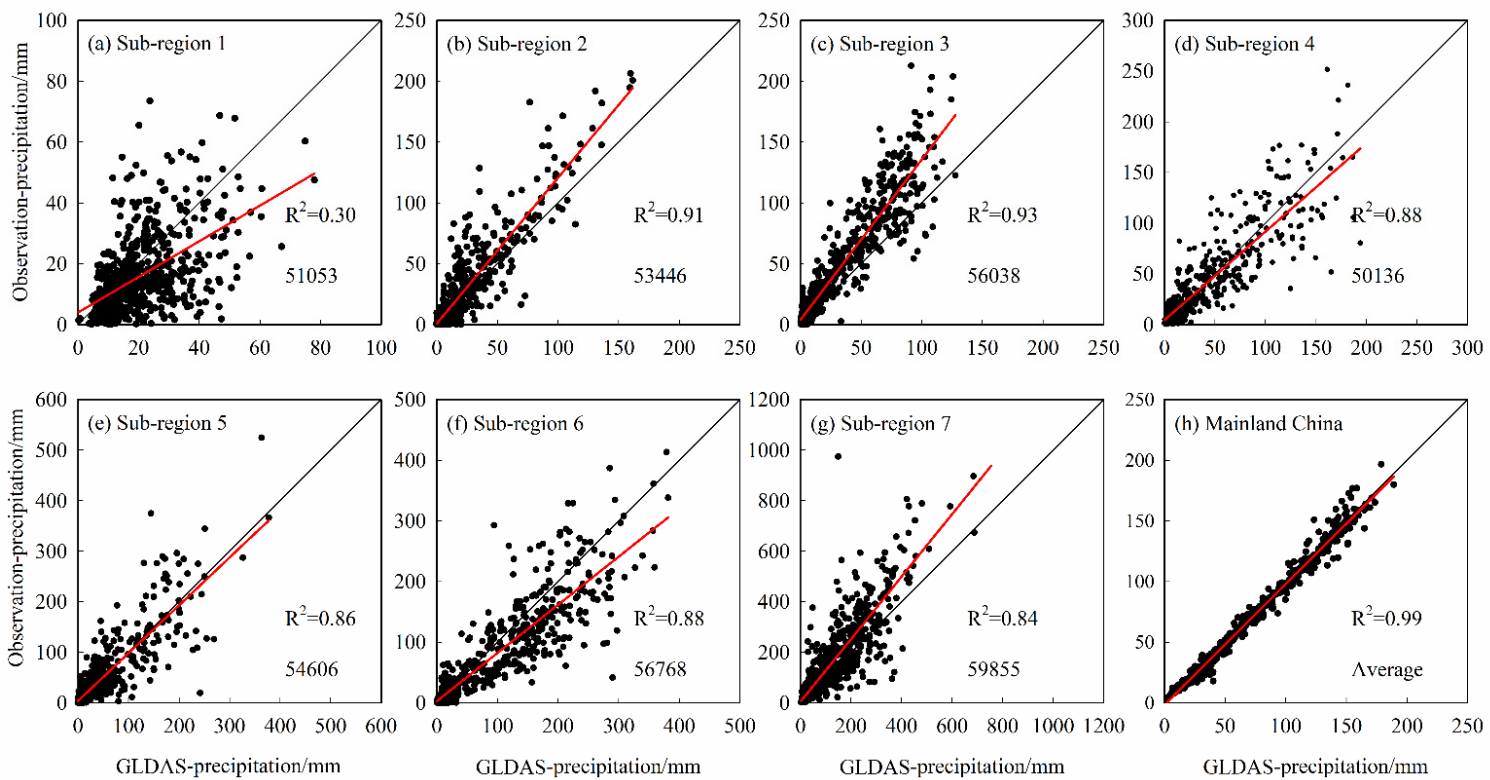

GLDAS-precipitation $/ \mathrm{mm}$

GLDAS-precipitation/mm

Figure 2. The scatter diagram of global land data assimilation system (GLDAS) and actual observed precipitation.

\subsection{The Computation of Standardized Precipitation Index (SPI), Standardized Soil Moisture Index (SSI), and Soil Runoff Index (SRI)}

2.3.1. Selection of Suitable Probability Density Functions of Spatiotemporal Variations of Precipitation (PPT), Soil Water Storage (SWS), and Baseflow-Groundwater Runoff (BGR)

Cumulative probability density function (PDF) is essential for calculating SPI, SSI, and SRI. Thus, the most suitable distribution types for monthly PPT, SWS, and BGR should be evaluated before transforming into standard normal distributions required for computing SPI/SSI/SRI. A set of 10 popular PDFs including the normal, two-parameter lognormal (LN2), three-parameter lognormal (LN3), generalized extreme value (GEV), Gumbel, Weibull, Poisson, Gamma, Pareto, and Pearson-III (P-III) distributions were fitted for each of PPT, SWS, and BGR data. Details on these PDFs including equations, parameters, and types can be found in Table 1 of Li et al. [36]. The parameters of the PDFs were estimated using linear moment (L-moment) method for each grid of the study area. 
Table 1. Grid number of the selected PDFs for spatiotemporal variations of precipitation (PPT), soil water storage (SWS), and baseflow-groundwater runoff (BGR) (assessed by the minimum Akaike information criterion (AIC) values).

\begin{tabular}{cccc}
\hline PDF & Precipitation & Soil Water Storage & Baseflow-Groundwater Runoff \\
\hline Gamma & 4124 & 367 & 4584 \\
GEV & 1489 & 8454 & 3140 \\
Gumbel & 1203 & 460 & 773 \\
LN2 & 12 & 983 & 1830 \\
LN3 & 2596 & 271 & 0 \\
Normal & 2026 & 1211 & 510 \\
P-III & 102 & 2574 & 1280 \\
Poiss & 582 & 95 & 0 \\
Weibull & 0 & 787 & 1589 \\
Pareto & 3068 & 0 & 848 \\
\hline
\end{tabular}

The PDF which fitted the empirical frequency curve the best (the one with the largest number of grids) was selected as a universal PDF for all three factors (PPT, SWS, and BGR). The coefficient of determination $\left(R^{2}\right)$, root mean squared error (RMSE), and Akaike information criterion (AIC) were used to compare the performance of the different PDFs:

$$
\begin{gathered}
R^{2}=\frac{\left[\sum_{i=1}^{n}\left(y m_{i}-\overline{y m}\right)\left(y_{i}-\bar{y}\right)\right]^{2}}{\sum_{i=1}^{n}\left(y m_{i}-\overline{y m}\right)^{2} \cdot \sum_{i=1}^{n}\left(y_{i}-\bar{y}\right)^{2}} \\
\text { RMSE }=\sqrt{\frac{\sum_{i=1}^{n}\left(y m_{i}-y_{i}\right)^{2}}{n}} \\
\text { AIC }=n \ln \left(\mathrm{RMSE}^{2}\right)+2 m
\end{gathered}
$$

where $y m_{i}$ and $y_{i}$ were empirical and theoretical frequencies, respectively; The $\overline{y m}$ and $\bar{y}$ were averaged values of $y m_{i}$ and $y_{i}$, respectively; $n$ was the total number of years, and $m$ was the number of parameters of cumulative distribution function. The $R^{2}$ showed the degree of covariation, RMSE assessed the degree of deviation, and AIC assessed the complexity of the estimated model and the goodness of the model-simulated data. The larger the values of $R^{2}$, or the lower the values of RMSE and AIC, the better the performance.

The optimal PDF of PPT, SWS, and BGR at the total 15,202 grid cells were mapped and are presented in Figure 3. The statistical parameters $R^{2}$, RMSE, and AIC of fitted 10 PDF for PPT, SWS, and BGR are presented in Table A1. It showed that Gamma, GEV, and Gamma/Weibull were preliminary selected as better/best PDFs for PPT, BGR, and SWS, respectively. In addition, the number of grids with the best performed PDFs for monthly PPT, SWS, and BGR are presented in Table 1. The Gamma, GEV, and Gamma distributions occupied the largest grid numbers out of the total grids for PPT, SWS, and BGR, respectively. Here sub-regional differences of the best PDFs were not considered because the Gamma, GEV, and Gamma distributions generally fitted well when compared with the empirical frequency curve for all the sub-regions. (see details in Figure A1). Therefore, using one PDF for the entire mainland China was reasonable as the most suitable distributions for further computing of SPI, SSI, and SRI [4,37]. 


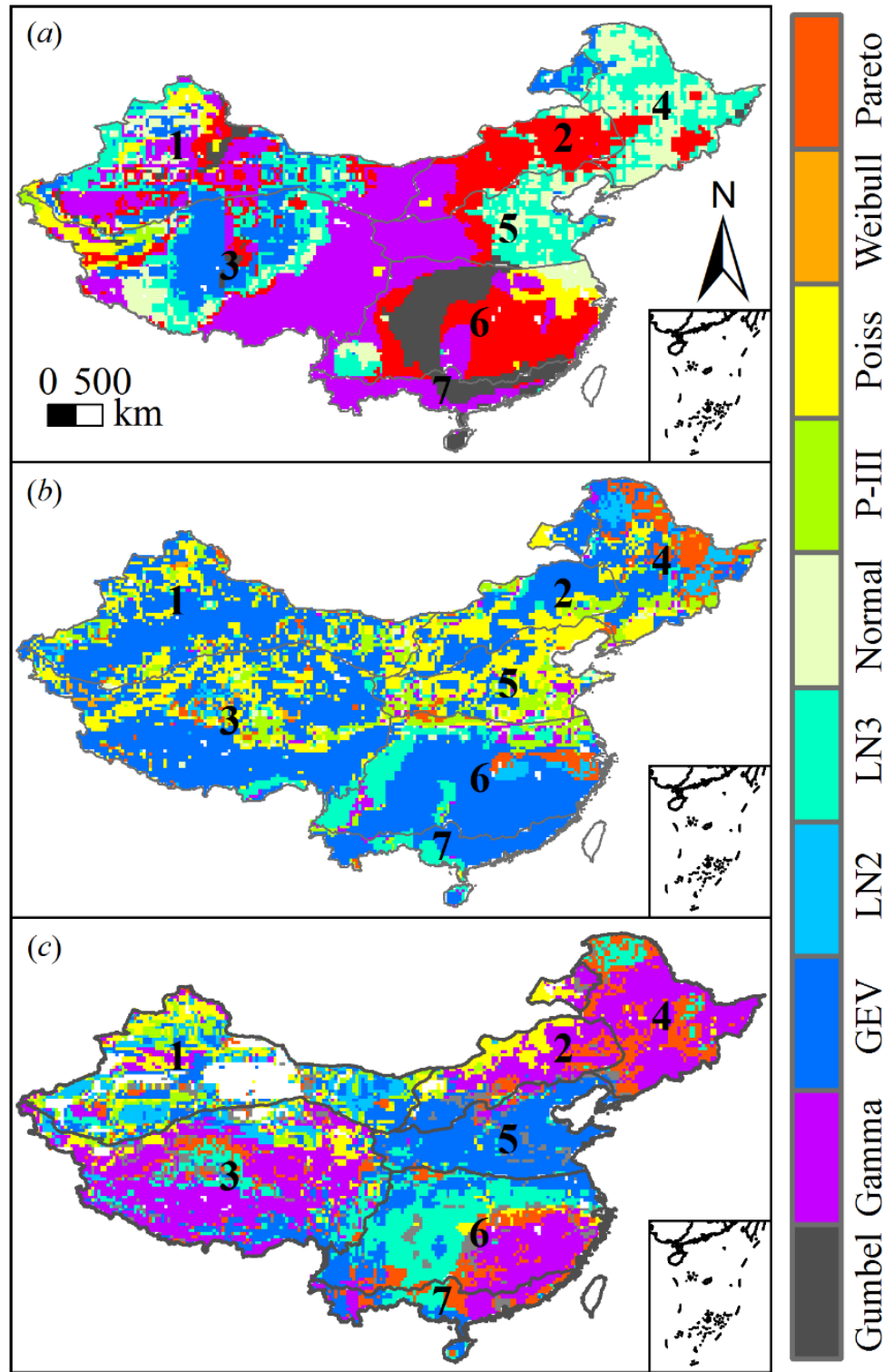

Figure 3. The spatial distribution of optimal probability density functions (PDFs) of monthly (a) precipitation, (b) soil water storage, and (c) baseflow-groundwater runoff.

\subsubsection{The Calculation of Standardized Drought Indices}

Although annual PPT, SWS, and BGR obeyed different frequency distributions, the calculation procedures of SPI, SSI, and SRI are generally similar. As PPT and BGR followed the Gamma distribution, the calculation of SPI and SRI were almost the same except for input data. SPI was calculated as:

$$
\text { SPI }=t-\frac{c_{0}+c_{1} t+c_{2} t^{2}}{1+d_{1} t+d_{2} t^{2}+d_{3} t^{3}}
$$

where $C_{0}=2.515517, C_{1}=0.802853, C_{2}=0.010328, d_{1}=1.432788, d_{2}=0.189269$, and $d_{3}=0.001308$, and $H(x)$ was the cumulative probability of monthly PPT. In order to account for zero value probability, we used $H(x)=q+(1-q) \mathrm{G}(x)$, where $q$ was the probability of zero PPT, $\mathrm{G}(x)$ was the PDF of Gamma defined for $x \neq 0$ [38]. For $H(x) \leq 0.5, t=\sqrt{\ln \left(\frac{1}{H(x)^{2}}\right)}$, for $H(x)>0.5, H(x)$ was replaced by $1-H(x)$ and the sign of SPI was reversed [39]. These parameters were obtained by McKee et al. [40]. 
Computation of SRI and SSI were similar to SPI computation. For details on SSI calculation, we refer readers to McKee et al. [40], Lloyd-Hughes and Saunders [41], and Yao et al. [42] and for SRI calculation we refer readers to Vicente-Serrano et al. [43], Hao et al. [44], and Shukla and Wood [45].

All three indices, SPI, SSI, and SRI were calculated at multiple timescales including 1-, 3-, 6-, 12-, and 24-months over the study period, January 1948 to December 2010. The SPI, SRI, and SSI were computed for each grid cell, each sub-region, and the entire mainland China to examine the spatial scale impact. Data for the historical drought events during 1961-2000 were collected from Ding [46]. The drought severity levels were classified based on the values of SPI, SSI, and SRI are presented in Table 2 [40].

Table 2. The classification of the drought severity levels according to Standardized Precipitation Index (SPI), Standardized Soil Moisture Index (SSI), and Soil Runoff Index (SRI).

\begin{tabular}{cc}
\hline SPI/SSI/SRI & Drought Severity Level \\
\hline$-0.5 \leq \mathrm{SPI} / \mathrm{SSI} / \mathrm{SRI}<0.5$ & Normal \\
$-1.0 \leq \mathrm{SPI} / \mathrm{SSI} / \mathrm{SRI}<-0.5$ & Mild drought \\
$-1.5 \leq \mathrm{SPI} / \mathrm{SSI} / \mathrm{SRI}<-1.0$ & Moderate drought \\
$-2.0 \leq \mathrm{SPI} / \mathrm{SSI} / \mathrm{SRI}<-1.5$ & Severe drought \\
$\mathrm{SPI} / \mathrm{SSI} / \mathrm{SRI}<-2.0$ & Extreme drought \\
\hline
\end{tabular}

\subsection{Time Series Analysis of SPI, SSI, and SRI}

\subsubsection{Trend Test Using the Modified Mann-Kendall Method}

The modified Mann-Kendall (MMK) method considers the significant self-correlation structure in the studied time series and tests trends based on the original non-parametric Mann-Kendall method [47-49]. The MMK method was applied to explore the tendency of SPI, SSI, SRI, and the related climatic variables at a significance level of 0.05 [50,51]. For detailed calculation procedures, we refer readers to Li et al. [52] and Shiru et al. [53].

\subsubsection{Periodical Characteristics Based on Wavelet Analysis}

Wavelet analysis uses a set of wavelet functions to represent signals [54]. It is a time-frequency localization analysis method with fixed window size but variable shape and was used in this research to study multi-time scale change characteristics. Continuous wavelet analysis is used in this paper to study and compare the periodicity of different droughts. For details on the procedures for applying continuous wavelet analysis, we refer readers to Biswas and Si [55], Li et al. [56], and Biswas [57].

Each standardized drought index had its main period, defined as the period with a maximum vibration intensity. The period could be significant or insignificant and was obtained from the bright color-belt of the wavelet contour map. The quasi-period defined as the period with secondary maximum vibration intensity was also determined.

\subsection{Correlation Analysis}

\subsubsection{Pearson Correlation Analysis between Pairs of SPI, SSI, and SRI}

Pearson correlation was applied to investigate the relationship between pairs of 12-month SPI, SSI, and SRI at the timescales of 1-, 3-, 6-, 12-, and 24-months. If the absolute value of Pearson correlation coefficient $(r)$ is close to 1 , the correlation is perfect. The smaller the $r$ value, the worse the connection between different drought indices. 


\subsubsection{Lag Time Analysis}

The lagged months is defined as the number of the months from which the SSI and SRI showed the highest correlation coefficients with SPI at the timescales of 1-, 3-, 6-, 12-, and 24-months. For specific definition and process of hysteresis, we refer readers to Ren et al. [58], $\mathrm{Xu}$ et al. [59], and Wen et al. [60].

Data analysis was conducted in Google Earth Engine, R studio 3.4.1, and MATLAB 2014a. Spatial distributions of different variables were mapped in ArcGIS 10.2 software.

\section{Results}

\subsection{Spatiotemporal Variations in PPT, SWS, and BGR}

\subsubsection{Temporal Variations}

The Annual Variations

Annual average PPT, SWS, and BGR in seven sub-regions are presented in Table 3. PPT increased from sub-region 1 through 7. However, SWS and BGR did not show similar increase, indicating variable soil storage and baseflow characteristics in different sub-regions.

Table 3. Annual average values of PPT, SWS, and BGR in seven sub-regions of China.

\begin{tabular}{|c|c|c|c|c|c|c|c|}
\hline $\begin{array}{l}\text { Sub-Region } \\
\text { Variable }\end{array}$ & 1 & 2 & 3 & 4 & 5 & 6 & 7 \\
\hline PPT (mm) & $103.4 \pm 8.4$ & $294.2 \pm 41.5$ & $400.2 \pm 22.7$ & $529.0 \pm 49.6$ & $539.0 \pm 65.7$ & $1176.3 \pm 88.0$ & $1468.5 \pm 134.8$ \\
\hline BGR (mm) & $1.2 \pm 0.1$ & $7.6 \pm 5.1$ & $100.9 \pm 17.0$ & $44.2 \pm 27.3$ & $51.3 \pm 28.1$ & $461.3 \pm 77.4$ & $637.9 \pm 113.2$ \\
\hline
\end{tabular}

The variations in annual PPT, SWS, and BGR over 1948-2010 in different sub-regions of China were compared (Figure 4). The changes of PPT, SWS, and BGR followed very similar fluctuation patterns within a sub-region, although their ranges differed. The ranges of PPT, SWS, and BGR also differed at different sub-regions. The annual SWS and BGR in sub-regions 1 and 2 were lower than the other five sub-regions due to less PPT. There were also time lags from PPT to SWS or BGR. For example, in sub-region 2, PPT achieved peak in 1959, while the SWS peaked in 1960, indicating an interannual lag between the annual PPT and the SWS. In addition, although there was no obvious interannual lag between the PPT and the BGR, the follow-up results showed that there was a lag between the two in the year. 

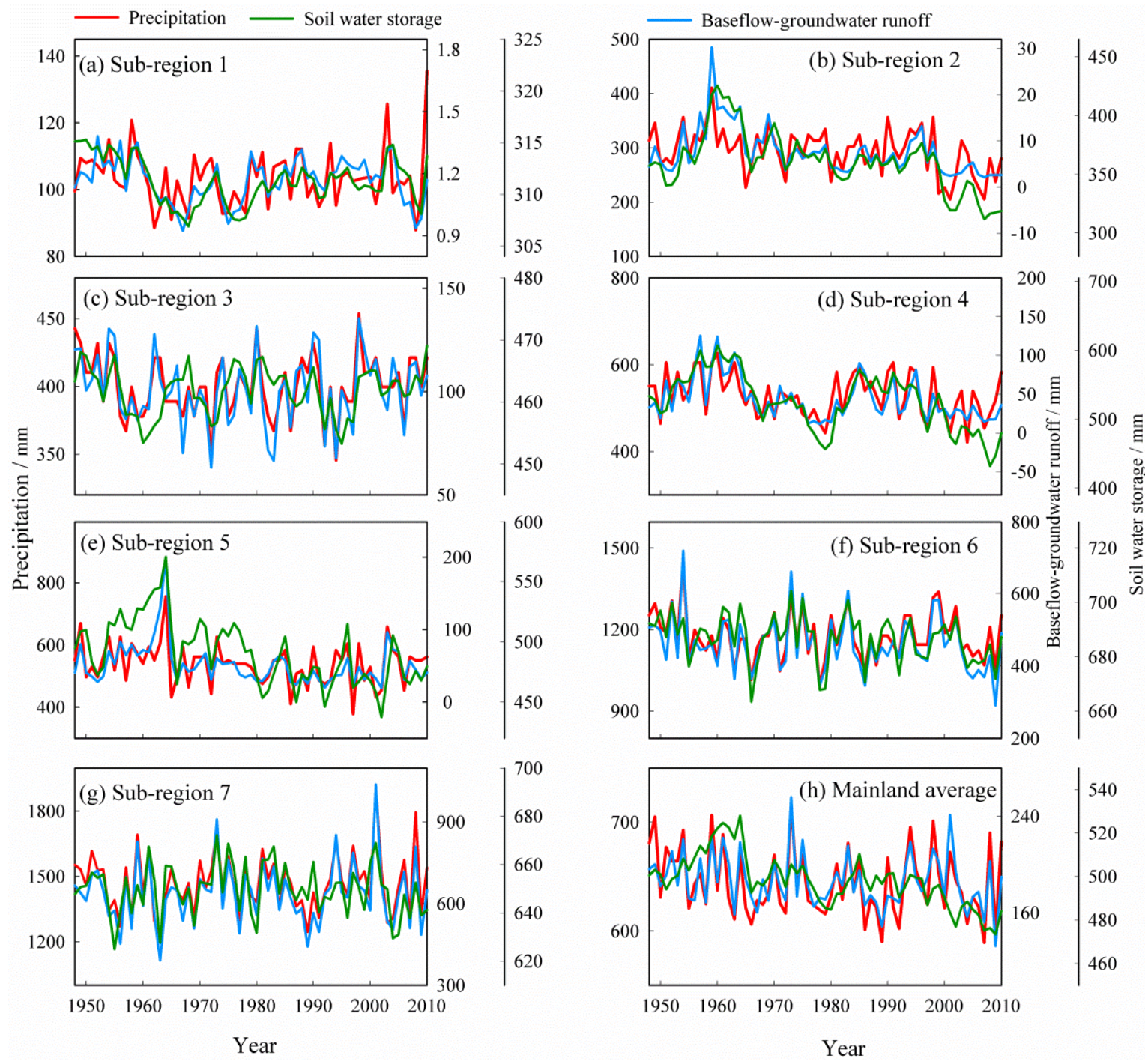

Figure 4. The variations of annual precipitation, soil water storage, and baseflow-groundwater runoff for different sub-regions and mainland China over 1948-2010.

The Annual Mean Monthly Variations

The annual mean (1948-2010) monthly values of PPT, SWS, and BGR showed a peak and valley pattern in all sub-regions except sub-region 7 (Figure 5). Two peaks were observed for sub-region 7 where monsoon climate prevailed and the weather was affected by 'Meiyu' (occurred from mid-June to early July) and typhoon (occurred from July to September). The lowest PPT, SWS, and BGR were observed during November-February because the climate in most of China is controlled by dry-cold northwest monsoon and sea vapor transport to the inland is limited. While higher amounts of PPT, SWS, and BGR were observed during June-September because the climate in summer was affected by the northward movement of direct solar point and the difference of thermal properties between land and sea. The western Pacific subtropical high (ridge) is becoming stronger and moving to the north. The warm moist air from the Pacific Ocean pushed by its northern tip brings precipitation to eastern China. The sub-region 1 (northwest China) received low precipitation ( $<200 \mathrm{~mm}$ annually) but had high potential and actual evapotranspiration ( $>1200 \mathrm{~mm}$ annually). The soil water storage was increased and had a peak around May since the air temperature increased the melted snow from Tianshan Mountains supplying water to the area. There were special cases in sub-regions 2, 4, and 5, where SWS had the lowest values in June (summer). This reflected a variable water storage 
characteristic of soil. In addition, there were time-lags from maximum PPT to maximum SWS or BGR for most sub-regions, indicating general duration of water movement and transfer processes.
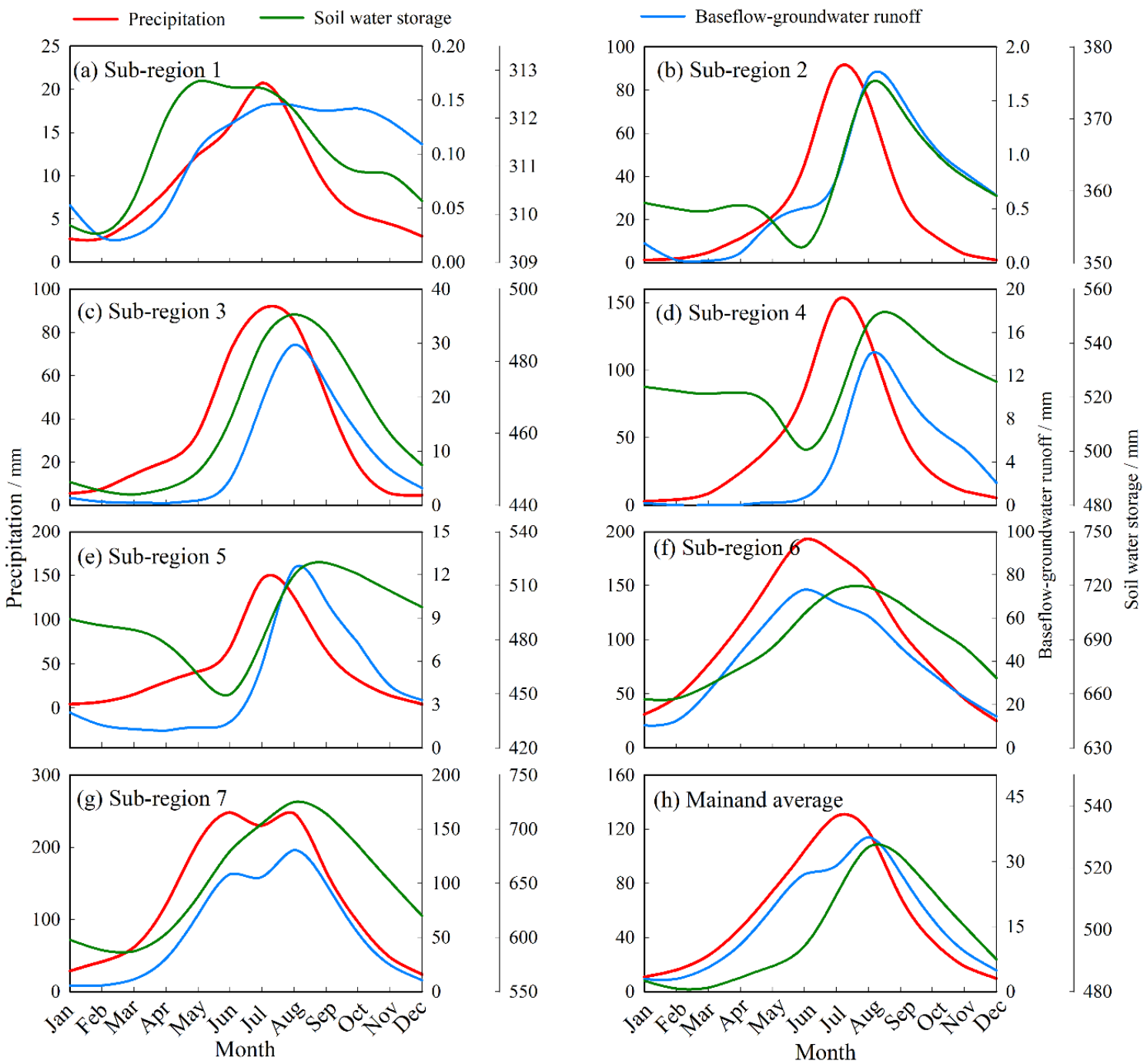

Figure 5. The annual mean (1948-2010) monthly variations of precipitation, soil water storage, and baseflow-groundwater runoff in different sub-regions and mainland China.

\subsubsection{The Spatial Distributions}

A general and consistent spatial distribution pattern was observed for PPT, SWS, and BGR (Figure 6). PPT, SWS, and BGR increased from the north-west to the south-east. The lowest PPT was recorded in northwest China and the largest PPT was observed in southeast China. This resulted in corresponding large areas of low SWS in northwest China and large areas of high SWS in southeast China (sub-regions 6 and 7). A high SWS was also observed in Northeast and Southwest China. The high BGR values were distributed in the coastal areas of southern China (sub-region 7). Overall, there was a strong spatial variability of PPT, SWS, and BGR. 


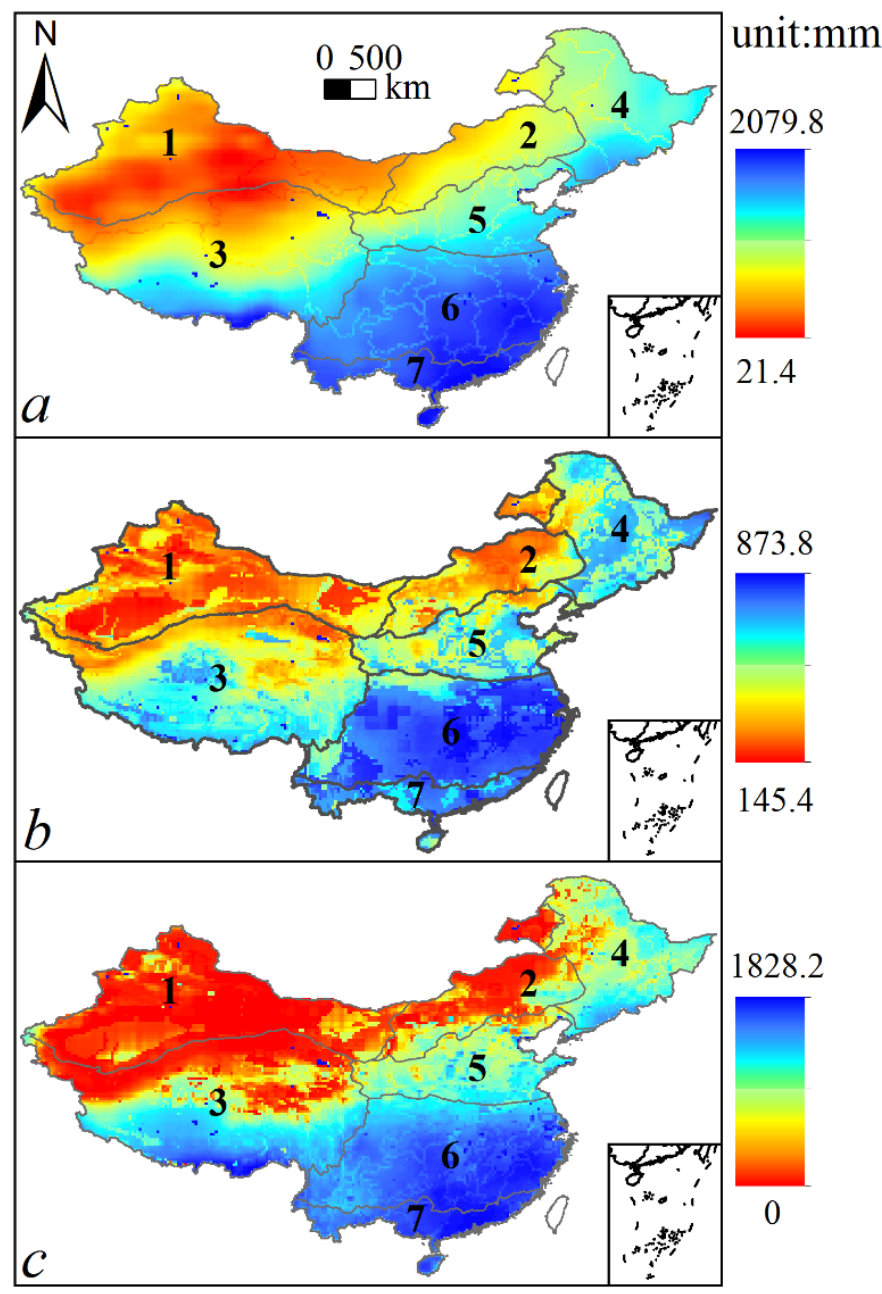

Figure 6. Spatial distribution of annual mean (averaged over 1948-2010) (a) precipitation, (b) soil water storage within 0-200 cm, and (c) baseflow-groundwater runoff in mainland China.

\subsection{The Drought Characteristics Represented by 12-month SPI, SSI, and SRI}

\subsubsection{Temporal Variations over $1948-2010$}

The temporal variations of 12-month SPI, SSI, and SRI over 1948-2010 in the seven sub-regions of China are presented in Figure 7. The historical drought events during 1961-2000 are also shown (black dots) in this figure. Except for sub-region 7, there were general increasing risks of drought worsening from 1950s to 2010s, especially for sub-regions 2, 4, and 5. The changes of 12-month SPI mostly reflected the historical (slight, moderate, severe, or extreme) drought events during 1961-2000 for most of the sub-regions. However, SPI, SSI, and SRI were not always consistent in denoting the dry/wet spells. For sub-region 1, SPI values were partially consistent with SSI and SRI over 1948-1958 but differed after 1958. SPI varied more than SSI and SRI during 1958-2010, which was reasonable since the baseflow in sub-region 1 was very small and was not strong enough to denote hydrological drought. The wet spells between 1958-1964 and the dry spells between 2001-2010 were similar for sub-regions 2 and 4, especially from SSI and SRI. The SSI showed less extreme wet/dry conditions than the SPI and SRI in sub-regions 1, 3, and 6. Sub-region 5 experienced longer dry spells than the other regions as frequent drought events were observed especially by SSI and SRI from 1979. This was on par with previous research related to north China drought [61-63]. There was more agreement and less lags among SPI, SSI, and SRI for sub-region 7 where annual precipitation was $>2000 \mathrm{~mm}$. In addition, the year 2009 witnessed severe droughts in sub-regions 2, 4, 6, and 7, which were observed from SPI, 
SSI, and SRI. This agreed well with the southwestern severe droughts from 2009-2012 [64-66]. Overall, the drought conditions differed for dry and wet areas.

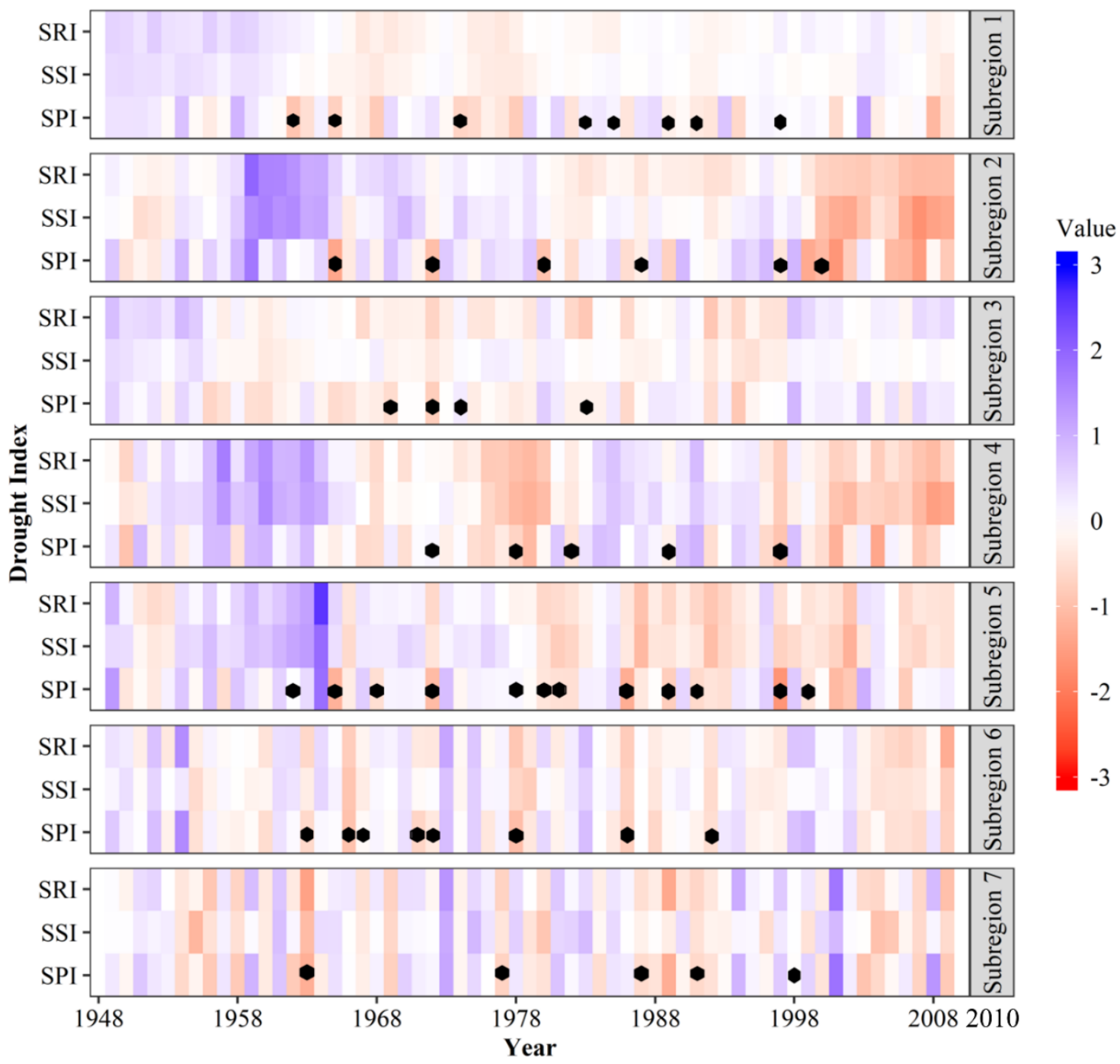

Figure 7. The temporal variations of 12-month SPI, SSI, and SRI over 1948-2010 compared with the historically-recorded severe or extreme drought events (1960-2000) in seven sub-regions of mainland China.

On the one hand, the historical drought events in each sub-region are investigated by the Chinese meteorological disasters pandect. These statistical materials only recorded the features and characteristics of drought but no detailed and accurate data since the official records are for the period before 2000. These records are not directly for different sub-regions but could be detailed to a county. On the other hand, the drought index for each sub-region is calculated by the averaged precipitation, baseflow-groundwater runoff, and soil moisture data over space. This averaged procedure may have introduced some undetectable deviations to the estimated drought index. In addition, the raw data source and the choice of cumulative probability function for estimating different drought indices may have also contributed to introducing some inevitable errors; thus causing mismatch between the drought index and the historical drought events

\subsubsection{The Trends}

The spatial distributions of the trends in the 12-month SPI, SSI, and SRI (tested by the MMK method) were mapped for mainland China and are presented in Figure 8. The trends of 12-month SSI and SRI 
distributed with high consistence in space, especially in northeast and northwest China. There were larger areas of significant decreasing trends (alleviated drought) in SSI and SRI than SPI. The 12-month SPI showed insignificant increasing trend in most regions, especially in western China, indicating long-term relief of drought. Large areas of insignificant increasing trends were observed for SSI and SRI in sub-region 3 (Qinghai-Tibet Plateau). For all of SPI, SSI, and SRI, more decreasing (significant or not) trends were observed in the eastern half of China, indicating the aggregation of metrological, agricultural, and hydrological droughts-especially the latter two. However, in northwestern China, SPI showed decreasing trends in most areas and indicated relief from metrological drought, but SSI and SRI showed both increasing and decreasing trends and indicated complex distributions of agricultural and hydrological droughts.

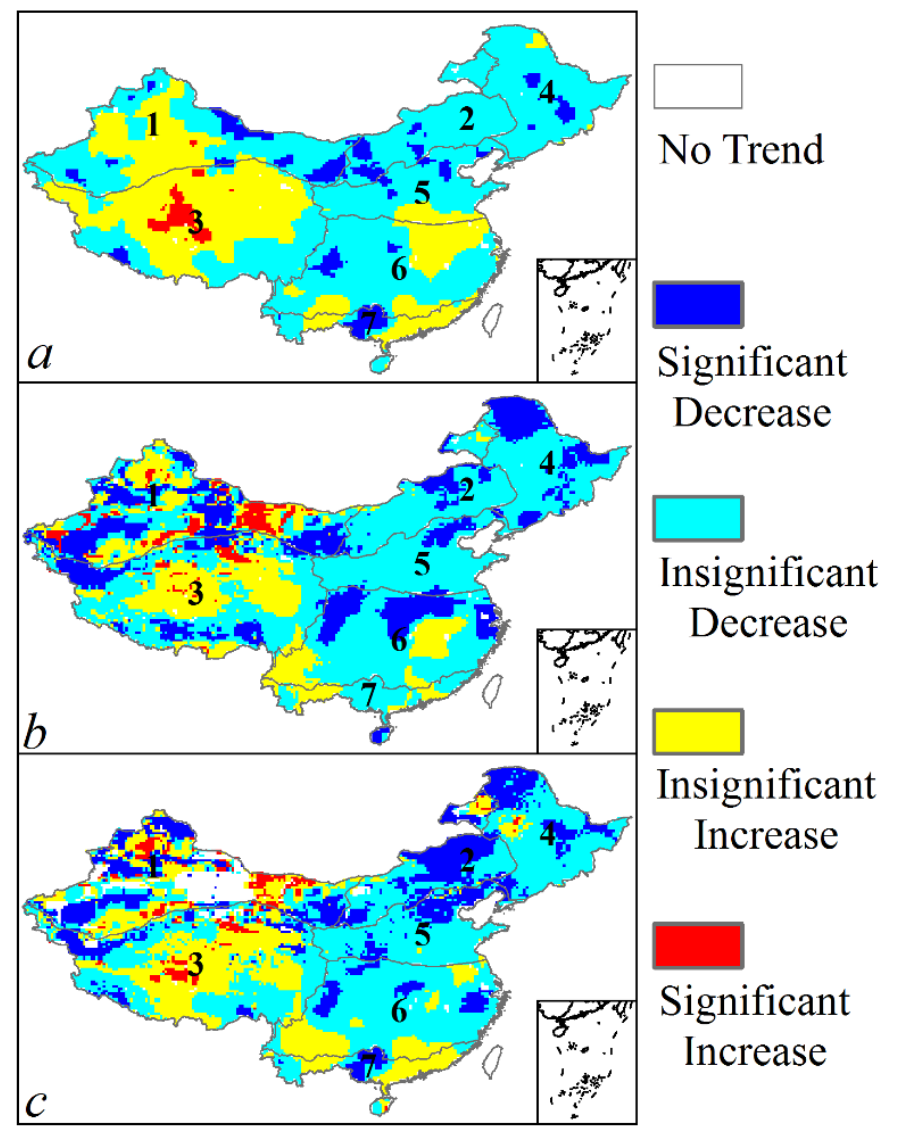

Figure 8. Spatial distributions of the trends in 12-month SPI, SSI, and SRI over 1948-2010 in China. (a) SPI, (b) SSI, and (c) SRI. Significant (insignificant)—passing (not passing) the signified test at the confidence level of $95 \%$ using the modified Mann-Kendall (MMK) test.

\subsubsection{The Periods}

The wavelet spectrum of the 12-month SPI, SSI, and SRI over 1948-2010 in seven different sub-regions are presented in Figure 9. The results showed that the main period varied when drought index or sub-region differed. From SPI, the main periods were 12, 20, 10, 12, 5, 8, and 8 years, and the quasi-periods were $8,6,6,5,8,14$, and 4 years for sub-regions 1 to 7 , respectively (Figure 9). From SSI, the main periods were $12,20,10,12,16,8$, and 12 years, and the quasi-periods were 8, 6, 6, 5, 8, 4 , and 6 years for sub-regions 1 to 7 , respectively (Figure 9). From SRI, the main periods were 8, 20, $10,12,16,8$, and 8 years, and the quasi-periods were 12, 10, 4, 3, 8, 4, and 12 years for sub-regions 1 to 7 , respectively (Figure 9). The SSI and SRI had similar main periods in four sub-regions $(2,3,4$, and 6), but had similar quasi-periods only in sub-region 5. In different durations, there were different 
significant periods. For example, in sub-region 5, there were significant periods of 1-4 years during 1960-1966 and of 4-6 years during 1996-2006 from SPI.
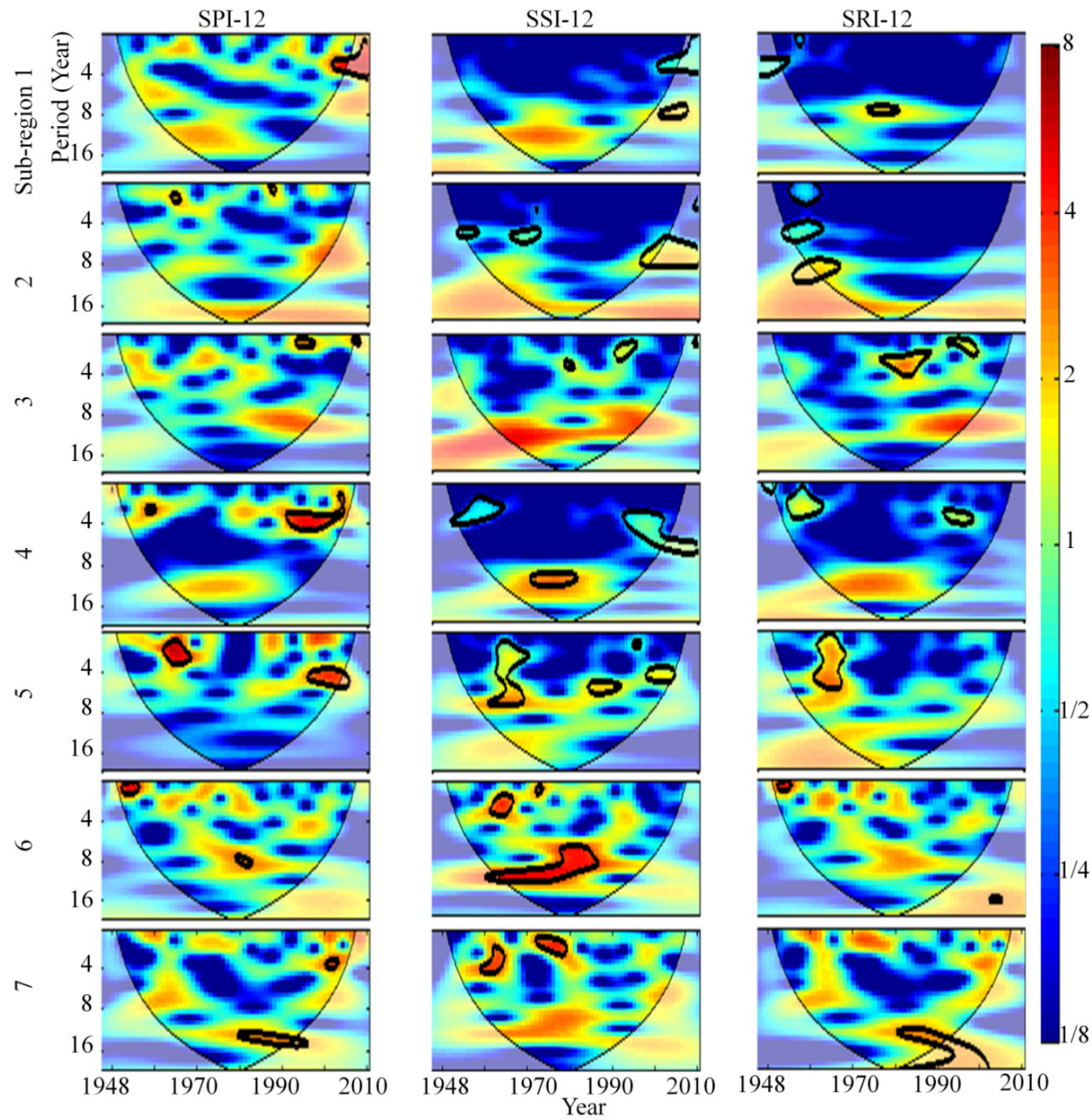

Figure 9. The wavelet spectra of the 12-month SPI, SSI, and SRI in different sub-regions of mainland China over 1948-2010. The thin solid lines denote the cones of influence, and the thick solid lines show the $95 \%$ confidence levels. The color bar means the vibration intensity of the periods at different timescales.

The spatial distribution of main period in the 12-month SPI, SSI, and SRI during the 1948-2010 were mapped for each grid of mainland China and are presented in Figure 10. For SPI, the periods with different time ranges (0-5, 5-10, 10-15, and 15-21 years) were distributed randomly over the mainland China. The period with a range of $0-5$ years occupied the largest areas. This suggested that the government should adapt to meteorological drought every 5 years. For SSI, periods with a range of 15-21 years occupied the largest areas and distributed mainly in the northern China, while the period with a range of $0-5$ years occupied the smallest areas and mostly distributed in the southeast China. It suggested that the government should take actions in tackling agricultural droughts every 10-15 years in northern China but every 5 years in southeast China. For SRI, the distribution of the main periods was like SSI but more dispersed. For example, the $0-5$ years covered more areas especially 
in south China. This suggested that the government should cope with hydrological drought according to the main-period changes in different regions.

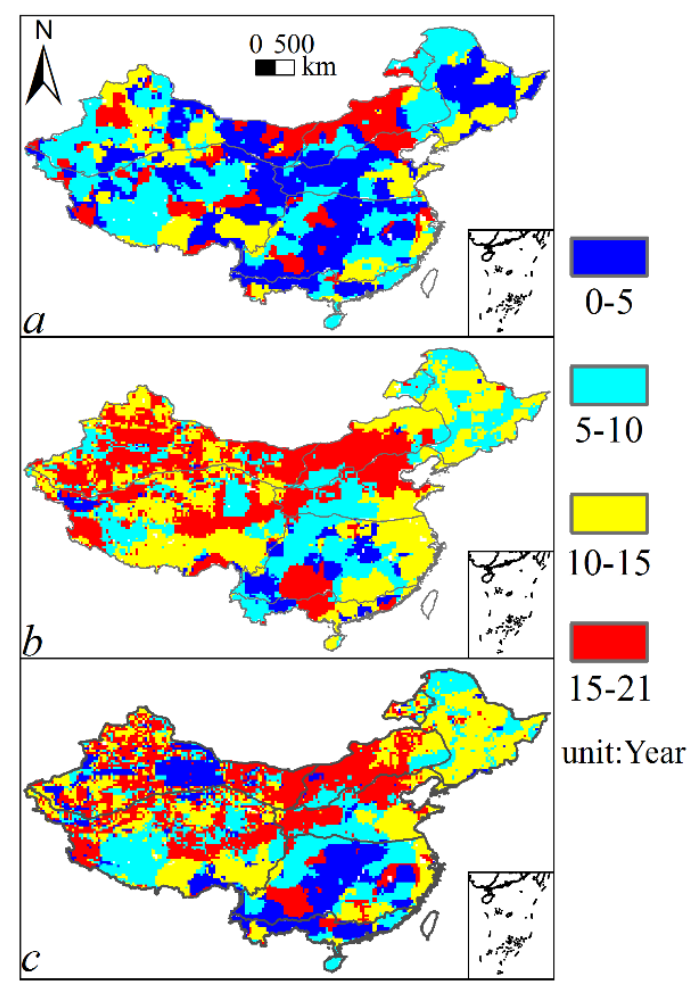

Figure 10. The spatial distribution of the main periods in the 12-month (a) SPI, (b) SSI, and (c) SRI over 1948-2010 for each grid in mainland China.

\subsection{The Associations between SPI and SSI/SRI}

The associations (Pearson correlation coefficient, $r$ ) between different types of droughts (SPI vs. SSI/SRI) over 1948-2010 at the 1-, 3-, 6-, 12-, and 24-month timescales in mainland China were mapped and are presented in Figure 11. All $r$ values were positive, showing a generally consistent trend of spatial variations of different types of drought. The $r$ values gradually increased from the north to the south of China. However, the $r$ values in northwestern China kept low $(r<0.5)$ at different timescales. This phenomenon occurred because precipitation was not a major factor affecting agricultural and hydrological droughts in northwestern China. In this region, there was low precipitation and large evapotranspiration (data were not shown). It also implied a low connection between meteorological drought and agricultural/hydrological droughts at short timescales in northwestern arid and semi-arid regions. The $r$ values between SPI and SSI (or SRI) were larger with an increase of timescales. The areas with $r>0.5$ increased as the timescale increased from 1- to 24-months since there was greater variability of drought indices at the shorter timescales. At a timescale, $r$ values of SPI vs. SSI were lower than that of SPI vs. SRI especially in south China. It was suggested that for studying the propagation of meteorological drought to agricultural or hydrological droughts, larger timescales should be preferred. 


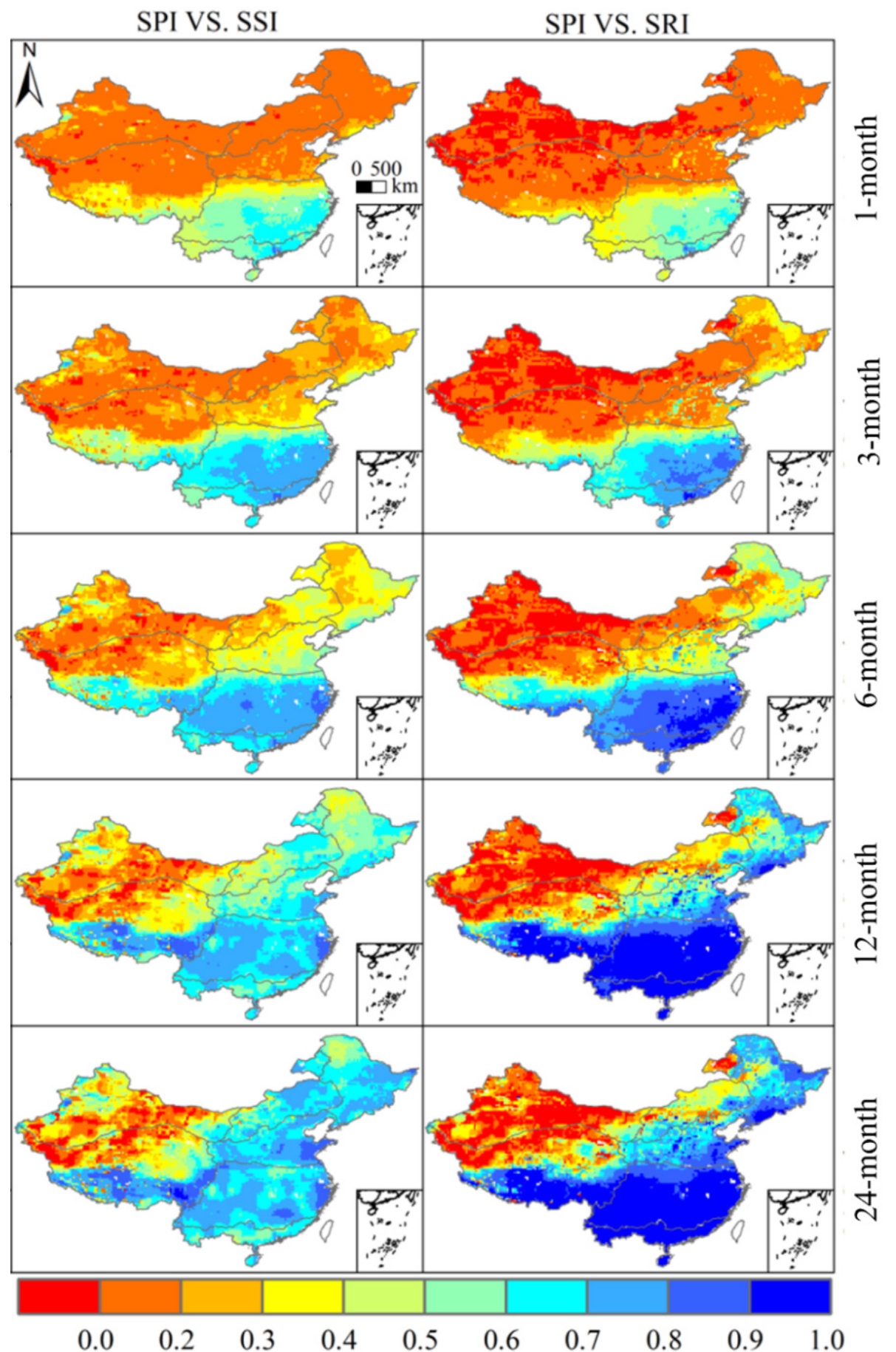

Figure 11. The spatial distributions of $r$ values between SPI and SSI (or SRI) over 1948-2010 at the 1-, 3-, $6-, 12-$, and 24-month timescales in mainland China.

The detail comparison of the $r$ values between SPI and SSI (or SRI) in different sub-regions are presented in Table 4. 
Table 4. The averaged $r$ values of between SPI and SSI (or SRI) at different timescales in seven sub-regions of China.

\begin{tabular}{cccccccccc}
\hline \multirow{2}{*}{$\begin{array}{c}\text { Timescale } \\
\text { (Month) }\end{array}$} & $\begin{array}{c}\text { Drought } \\
\text { Index }\end{array}$ & $\mathbf{1}$ & $\mathbf{2}$ & $\mathbf{3}$ & $\mathbf{4}$ & $\mathbf{5}$ & $\mathbf{6}$ & $\mathbf{7}$ & MC \\
\cline { 3 - 10 } & SPI SSI & 0.12 & 0.11 & 0.19 & 0.14 & 0.17 & 0.51 & 0.56 & 0.26 \\
\multirow{2}{*}{1} & SPI SRI & 0.00 & 0.04 & 0.10 & 0.12 & 0.09 & 0.44 & 0.50 & 0.18 \\
& SPI SSI & 0.15 & 0.19 & 0.27 & 0.24 & 0.27 & 0.65 & 0.67 & 0.35 \\
\multirow{2}{*}{3} & SPI SRI & 0.00 & 0.09 & 0.19 & 0.27 & 0.21 & 0.66 & 0.71 & 0.30 \\
& SPI SSI & 0.19 & 0.33 & 0.35 & 0.36 & 0.41 & 0.71 & 0.69 & 0.43 \\
\multirow{2}{*}{6} & SPI SRI & 0.02 & 0.19 & 0.31 & 0.42 & 0.39 & 0.80 & 0.86 & 0.43 \\
& SPI SSI & 0.25 & 0.54 & 0.42 & 0.55 & 0.60 & 0.71 & 0.64 & 0.53 \\
\multirow{2}{*}{12} & SPI SRI & 0.07 & 0.36 & 0.45 & 0.64 & 0.64 & 0.91 & 0.94 & 0.57 \\
\hline \multirow{2}{*}{24} & SPI SSI & 0.29 & 0.65 & 0.46 & 0.65 & 0.72 & 0.71 & 0.64 & 0.59 \\
& SPI SRI & 0.12 & 0.45 & 0.50 & 0.72 & 0.73 & 0.93 & 0.96 & 0.63 \\
\hline
\end{tabular}

\subsection{The Spatial Pattern of Lagged Months at Different Timescales}

The correlations of SPI with SSI or SRI differed with locations (grids) and timescales. Taking $r=0.5$ as a standard, the number of the grids with $r>0.5$ for SPI with SSI or SRI at different timescales are presented in Table 5. The number of grids with $r>0.5$ for pairs of drought indices increased with increasing lag time at the timescales of 1-, 3-, 6-, 12-, and 24-months.

Table 5. The number of grids with $r>0.5$ between SPI and SSI or SRI at different timescales.

\begin{tabular}{|c|c|c|c|c|c|c|c|}
\hline \multirow{2}{*}{$\begin{array}{l}\text { Timescale } \\
\text { (Month) }\end{array}$} & \multirow{2}{*}{$\begin{array}{l}\text { Drought } \\
\text { Index }\end{array}$} & \multicolumn{6}{|c|}{ Lag Time (Month) } \\
\hline & & $\mathbf{0}$ & 1 & 2 & 3 & 4 & 5 \\
\hline \multirow{2}{*}{1} & SPI SSI & 2408 & 0 & 0 & 0 & 0 & 0 \\
\hline & SPI SRI & 1474 & 0 & 0 & 0 & 0 & 0 \\
\hline \multirow{2}{*}{3} & SPI SSI & 3958 & 85 & 0 & 0 & 0 & 0 \\
\hline & SPI SRI & 3600 & 87 & 0 & 0 & 0 & 0 \\
\hline \multirow{2}{*}{6} & SPI SSI & 5141 & 3325 & 546 & 7 & 0 & 0 \\
\hline & SPI SRI & 5464 & 3823 & 875 & 0 & 0 & 0 \\
\hline \multirow{2}{*}{12} & SPI SSI & 8868 & 7326 & 5388 & 2888 & 1082 & 283 \\
\hline & SPI SRI & 8296 & 7665 & 7057 & 6256 & 4812 & 1862 \\
\hline \multirow{2}{*}{24} & SPI SSI & 10,371 & 9937 & 9323 & 8505 & 7499 & 6307 \\
\hline & SPI SRI & 9214 & 9024 & 8795 & 8480 & 8012 & 7579 \\
\hline
\end{tabular}

Figure 12 shows the spatial distribution of the most suitable lagged months (with the largest $r$ values) of SSI (agricultural drought) and SRI (hydrological drought) from SPI (meteorological drought) in mainland China at the five timescales of 1-, 3-, 6-, 12-, and 24-months. The most suitable lag time from SPI to SSI (or SRI) distributed similarly for different timescales. In large areas, especially south China there was less than 1-month of lag time between SSI (or SRI) and SPI. However, as the timescale increased, the areas of longer lag time from SPI to SSI (or SRI) decreased. This means that there was less and less lagged time from meteorological to agricultural or hydrological droughts in most regions of China. In most areas, the meteorological drought propagated to agricultural and hydrological droughts quickly (less than 1-month). However, in northwestern China where annual precipitation is low $(<150 \mathrm{~mm})$ but evapotranspiration is high $(>100 \mathrm{~mm})$, the lags between agricultural drought and hydrological drought were longer. This indicated that in these regions the propagation of meteorological to agricultural or hydrological droughts was relatively slow. This implied that in southeastern and 
south China, attentions of drought adaption should be not only payed to meteorological drought, but also to agricultural and hydrological droughts.

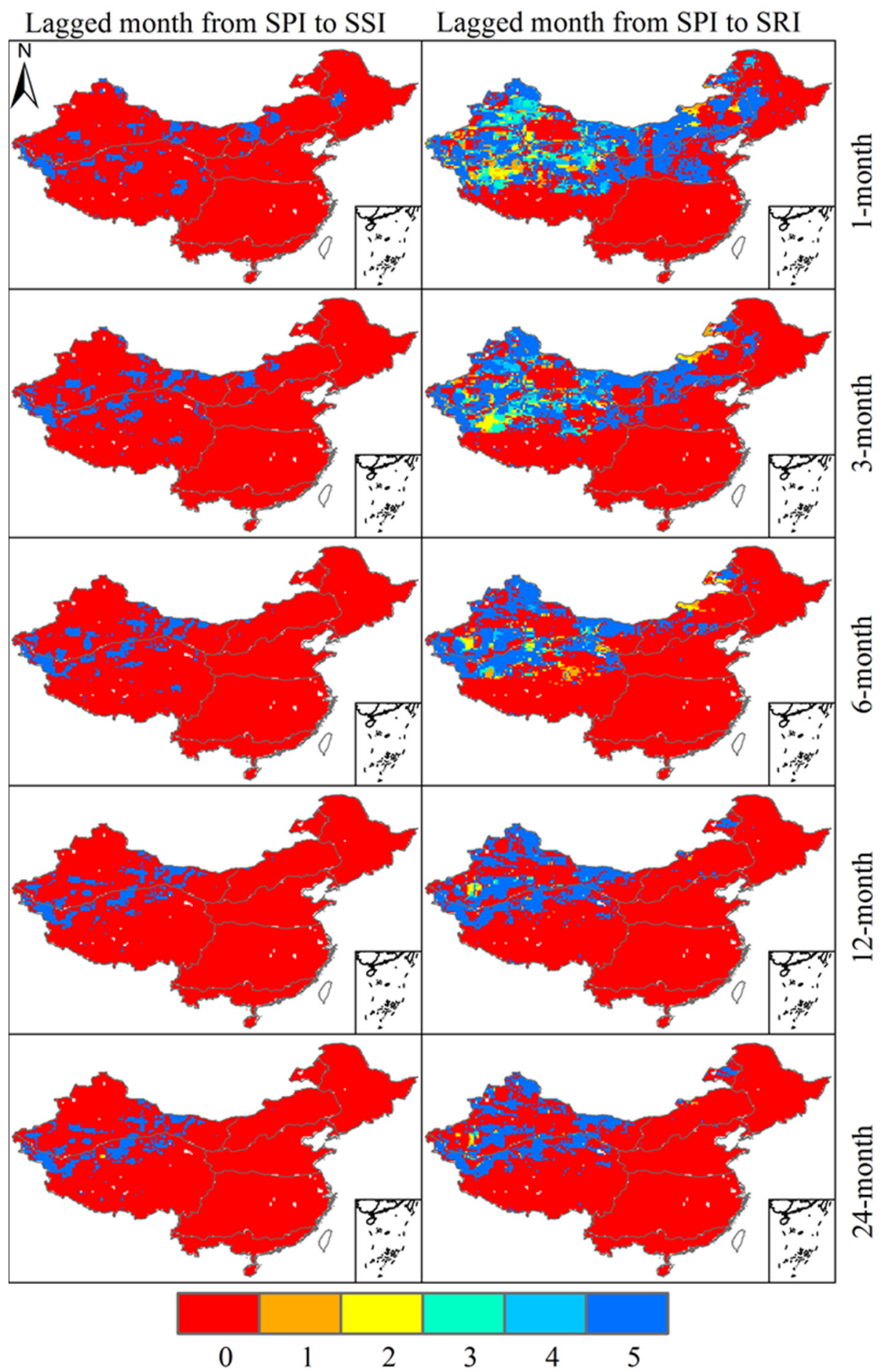

Figure 12. Spatial patterns of lag time (in months) from SPI to SSI or SRI at the five timescales of 1-, 3-, 6-, 12-, and 24-months in mainland China over 1948-2010.

\section{Discussion}

Information on the spatial and temporal distribution of drought is critical to understand the hazards associated and develop strategies against it. This requires detailed information on the temporal and spatial changes of determining factors including PPT, SWS, and BGR $[2,67,68]$ and the probability 
density functions can provide information on their variability. This study quantified the variations and probability density functions of PPT, SWS, and BGR for further computing drought indices of SPI, SSI, and SRI. This provided rational references for obtaining close-to-real drought indices which decreased to the least. However, many studies computed the standardized drought indices using the original density functions. For example, Yao et al. [42], Sun et al. [69], and Lai et al. [70] used the acquiescent distributions and calculated the SPEI, SPI, SSI, and SRI and evaluated the drought occurrence features without selecting the most suitable probability density function. Unlike the current study, inclusion of a fixed function without considering data specificity may have introduced some errors in drought indicators estimated in the previous studies.

Similarly, previous studies mostly focused on the comparison between meteorological and agricultural (or hydrological) droughts [13,71,72]. The studies of drought propagation were limited to some extent due to data limitation and technology complexity. Li et al. [73] studied meteorological and hydrological droughts in the Red River Basin of Yunnan Province in China using SPEI and streamflow drought index. They reported that the hydrological drought lagged meteorological drought by 1-8 months. Ma'rufah et al. [71] analyzed the relationship between SPI and VHI. They reported that meteorological and agricultural droughts were more intensive during the El Niño years. In addition, the meteorological drought mainly occurred during June and November whereas the agricultural drought mostly occurred from August to November. Huang et al. [10] explored the transmission time from meteorological to hydrological droughts and the influencing factors in Weihe River Basin of China and underlying surface condition based on $\mathrm{Fu}$ [74]. The results showed that the propagation time in spring and summer was shorter than that in autumn and winter. In addition, El Nino and Southern Oscillation had great influences on the propagation time. Wu et al. [13] proposed a theoretical model of the propagation from meteorological to hydrological drought. However, due to the limitation in number of stations, the theoretical model cannot be widely used in other regions. In this research, the most suitable propagation time from meteorological to agricultural or to hydrological droughts was investigated, which improved our understanding to respond to timely propagation of meteorological drought to agricultural or hydrological droughts. This also provided critical information in drought forecasting or assessment of the impacts of drought on crop and livestock productions.

Since the propagation of meteorological to agricultural and hydrological droughts is non-linear and complex [37], the response of meteorological drought to hydrological cycle differed for different sub-regions. Not only is the propagation time of drought useful, the factors that affect the propagation time of drought is also important. Although we investigated the characteristics and propagation of different types of drought, the frequency, duration, and magnitude, which depicted more respects of drought occurrence based on the run theory have not been systematically revealed considering the limitation of the article length. In future studies, the analysis of the driving factors of drought formation and propagation or run theory-based drought variable analysis are recommended. In addition, the quantitative description of drought propagation time and the factors influencing drought transmission will be indispensable to develop reasonable measures in tackling and adapting to drought.

Drought is caused by several complicated processes changing generally from meteorological to agricultural to hydrological drought with some intrinsically related process. By comparing the correlation coefficients in different areas of different drought indices, we monitored different types of drought. It implied that we must take measures to cope with local drought. For example, precipitation varies in different locations of China [75]. When the precipitation is low or the continuous evapotranspiration is large, southern China with a large correlation between different drought types should adapt farmland irrigation and river basin water storage at an early stage to avoid the impact of agricultural hydrological droughts.

\section{Conclusions}

Drought is very complex and one of the most damaging natural disasters. The interconnection between different types of droughts, their spatiotemporal distribution and propagation characteristics 
at multiple scales, and the dominant time lag are critical for developing policies and strategies for responding to drought hazards. This study provided a comprehensive analysis and assessment of meteorological, agricultural, and hydrological droughts, their spatiotemporal distribution, and propagation characteristics at multiple time scales. Three drought indices, SPI, SSI, and SRI representing meteorological, agricultural, and hydrological droughts were calculated based on PPT, SWS, and BGR characteristics. Strong spatial variability in the PPT, SWS, and BGR and the drought indices were observed across mainland China with distinct time lags.

The temporal variations of 12-month SPI, SSI, and SRI over 1948-2010 indicated generally increasing risks of drought in six out of seven sub-regions but were not always consistent in denoting the dry/wet spells for different sub-regions. For all of SPI, SSI, and SRI, more decreasing (significant or not) trends were observed in the eastern half of China, indicating the aggregation of metrological, agricultural, and hydrological droughts, especially SSI and SRI. The meteorological drought was worsened mainly in southwestern China, while the agricultural and hydrological droughts were worsened in northwestern China. The main periods of agricultural and hydrological droughts were larger than for meteorological droughts, and the spatial distribution characteristics of the main periods of agricultural and hydrological drought were similar. The varied main periods of different types of drought in different sub-regions implied that the government should take location and time tailored approaches to cope with droughts. Low correlation between SPI and SSI or SRI was observed at northwestern China, indicating a low connection between meteorological and agricultural/hydrological droughts at short timescales in northwestern arid and semi-arid regions. Additionally, the lags between agricultural and hydrological droughts were longer in northwestern China than in south China, indicating slow propagation of meteorological to agricultural or hydrological droughts in aridand semi-arid regions. The faster propagation of meteorological droughts in south China implied that the drought adaption should not only be paying attention to meteorological drought, but also to agricultural and hydrological droughts.

The spatiotemporal distribution of droughts, identification of causal factors, the developments and propagation characteristics can only provide critical information necessary to develop strategies for managing and tackling droughts. The information generated in this study will help managers and policymakers to better intervene in the process of drought transmission, weaken or even avoid the impact of drought transmission, and analyze the multi time scale. The trend of drought at multiple time scales and at different regions will help understand the situations and forecast regional future droughts.

These results are useful for policymakers and decision-makers. For example, when meteorological drought onset with continuous dry days, the water resources management department should adjust water allocation ratio and amount or set up a rational reservoir water level. These results could be also integrated with future climate change projections to better forecast droughts by using the newly released data of Global Climate Model in the Coupled Model Intercomparison Project Phase 6.

There are some limitations in this research. First, the modeled data caused errors in drought analysis. Second, the intrinsic mechanics of drought propagation has not been revealed. Future study will focus on revealing the mechanics of drought propagation from one type to another in China.

Author Contributions: Conceptualization, H.Z.; methodology, Y.L. and A.B.; validation, A.B. and B.P.; resources, H.F.; writing-original draft preparation, N.Y. and H.Z.; writing—review and editing and F.L., Y.L.; funding acquisition, Y.L. All authors have read and agreed to the published version of the manuscript.

Funding: This research was funded by the Key Research and Development Program of China (No. 2019YFA0606902), Natural Science Foundation of China (No. 52079114) and the China 111 project (No. B12007).

Conflicts of Interest: The authors declare that they have no conflict of interest.

\section{Abbreviations}

PPT: Precipitation; SWS, Soil Water Storage; BGR, Baseflow-Groundwater Runoff; NDWI, Normalized Difference Water Index; SPI, Standardized Precipitation Index; SSI, Standardized Soil Moisture Index; SRI, Standardized Runoff Index. 


\section{Appendix A}

Table A1. Statistical parameters that showed the performance of ten PDFs fitting PPT, BGR and SSW.

\begin{tabular}{|c|c|c|c|c|c|c|c|c|c|c|}
\hline \multirow{2}{*}{ Variable } & \multirow{2}{*}{ PDF } & \multicolumn{3}{|c|}{$R^{2}$} & \multicolumn{3}{|c|}{ RMSE } & \multicolumn{3}{|c|}{ AIC } \\
\hline & & Max & Min & Mean & Max & Min & Mean & Max & Min & Mean \\
\hline \multirow{10}{*}{ PPT } & Gamma & 1.00 & 0.79 & 0.98 & 0.159 & 0.005 & 0.046 & -2776 & -8038 & -4819 \\
\hline & GEV & 1.00 & 0.57 & 0.97 & 0.360 & 0.008 & 0.052 & -1538 & -7352 & -4673 \\
\hline & Pareto & 1.00 & 0.70 & 0.97 & 0.177 & 0.007 & 0.057 & -2614 & -7407 & -4466 \\
\hline & Gumbel & 0.99 & 0.63 & 0.83 & 0.204 & 0.027 & 0.125 & -2396 & -5466 & -3176 \\
\hline & LN2 & 1.00 & 0.63 & 0.97 & 0.188 & 0.010 & 0.053 & -2523 & -6934 & -4562 \\
\hline & LN3 & 1.00 & 0.51 & 0.96 & 0.236 & 0.006 & 0.053 & -2177 & -7836 & -4687 \\
\hline & Norm & 1.00 & 0.67 & 0.88 & 0.178 & 0.018 & 0.101 & -2604 & -6074 & -3547 \\
\hline & P3 & 1.00 & 0.72 & 0.94 & 0.192 & 0.004 & 0.068 & -2492 & -8189 & -4293 \\
\hline & Poiss & 0.98 & 0.65 & 0.78 & 0.337 & 0.069 & 0.268 & -1641 & -4030 & -2025 \\
\hline & Weibull & - & - & - & - & - & - & - & - & - \\
\hline \multirow{10}{*}{ SWS } & Gamma & 1.00 & 0.44 & 0.98 & 0.223 & 0.005 & 0.041 & -2262 & -8010 & -5074 \\
\hline & GEV & 1.00 & 0.84 & 0.99 & 0.162 & 0.004 & 0.027 & -2745 & -8344 & -5679 \\
\hline & Pareto & - & - & - & - & - & - & - & - & - \\
\hline & Gumbel & 1.00 & 0.58 & 0.96 & 0.206 & 0.010 & 0.062 & -2379 & -6911 & -4368 \\
\hline & LN2 & 1.00 & 0.44 & 0.98 & 0.223 & 0.005 & 0.041 & -2260 & -8063 & -5078 \\
\hline & LN3 & 1.00 & 0.44 & 0.98 & 0.223 & 0.005 & 0.041 & -2260 & -8063 & -5076 \\
\hline & Norm & 1.00 & 0.45 & 0.98 & 0.222 & 0.005 & 0.042 & -2267 & -8079 & -5039 \\
\hline & P3 & 1.00 & 0.87 & 0.99 & 0.136 & 0.005 & 0.030 & -3016 & -8090 & -5611 \\
\hline & Poiss & 1.00 & 0.42 & 0.94 & 0.273 & 0.010 & 0.134 & -1959 & -7013 & -3201 \\
\hline & Weibull & 1.00 & 0.58 & 0.96 & 0.208 & 0.007 & 0.056 & -2367 & -7505 & -4540 \\
\hline \multirow{10}{*}{ BGR } & Gamma & 1.00 & 0.04 & 0.93 & 0.297 & 0.007 & 0.080 & -1830 & -7445 & -4019 \\
\hline & GEV & 1.00 & 0.04 & 0.92 & 0.524 & 0.005 & 0.102 & -971 & -7887 & -4020 \\
\hline & Pareto & 1.00 & 0.04 & 0.92 & 0.520 & 0.007 & 0.088 & -988 & -7516 & -3943 \\
\hline & Gumbel & 1.00 & 0.03 & 0.68 & 0.289 & 0.015 & 0.167 & -1871 & -6335 & -2812 \\
\hline & LN2 & 1.00 & 0.04 & 0.91 & 0.286 & 0.006 & 0.081 & -1889 & -7681 & -4071 \\
\hline & LN3 & - & - & - & - & - & - & - & - & - \\
\hline & Norm & 1.00 & 0.04 & 0.76 & 0.286 & 0.012 & 0.141 & -1889 & -6648 & -3077 \\
\hline & P3 & 1.00 & 0.04 & 0.87 & 0.533 & 0.005 & 0.127 & -945 & -7925 & -3436 \\
\hline & Poiss & - & - & - & - & - & - & - & - & - \\
\hline & Weibull & 1.00 & 0.04 & 0.93 & 0.284 & 0.008 & 0.076 & -1899 & -7336 & -4112 \\
\hline
\end{tabular}



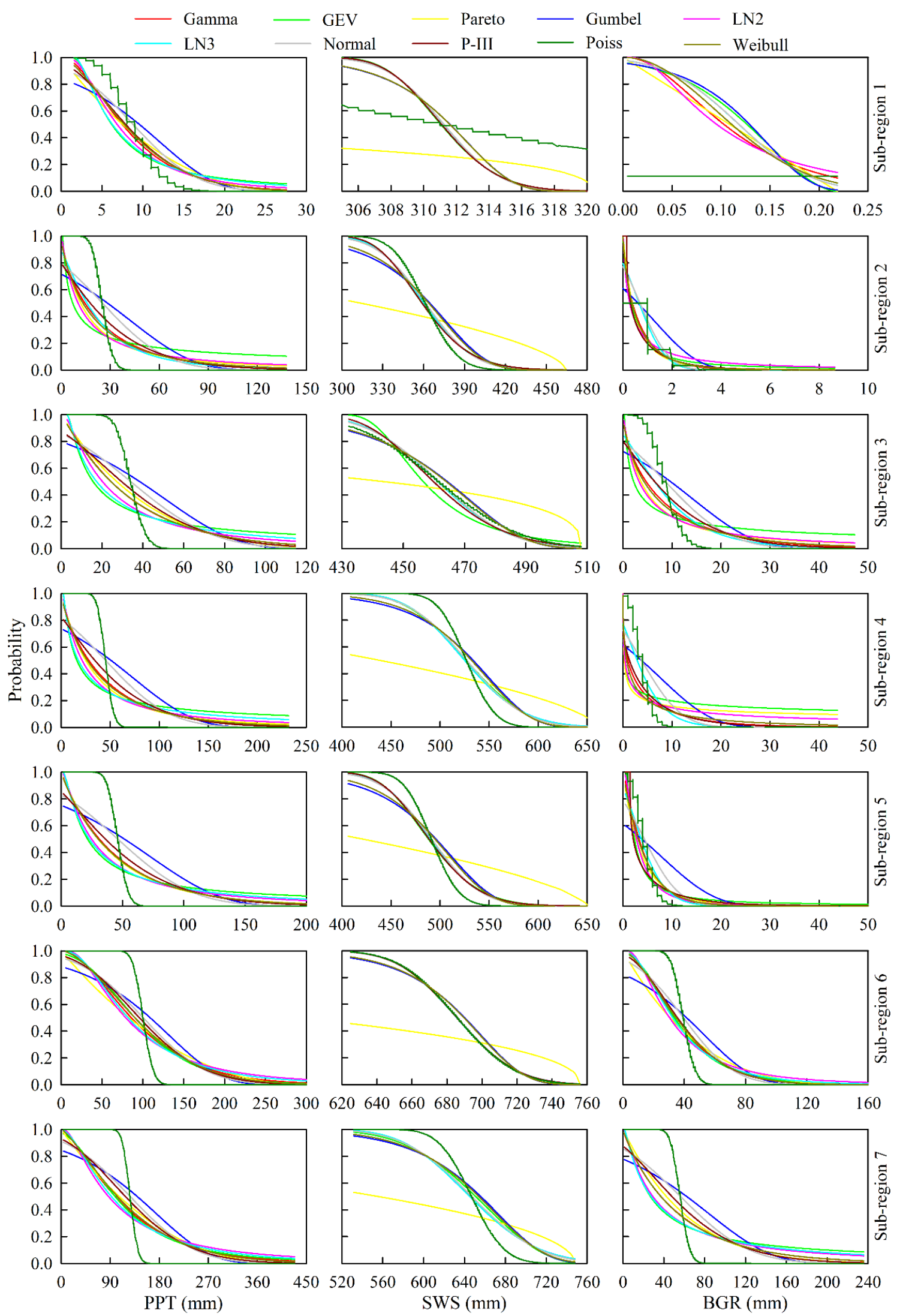

Figure A1. The curves of the 10 PDFs for PPT, BGR, and SWS in seven different subregions of China. 


\section{References}

1. EU. Addressing the Challenge of Water Scarcity and Droughts in the European Union, Communication from the Commission to the European Parlement and the Council; European Commission, DG Environment: Brussels, Belgium, 2007.

2. Dracup, J.A.; Lee, K.S.; Paulson, E.G. On the definition of droughts. Water Resour. Res. 1980, 16, $297-302$. [CrossRef]

3. Wilhite, D.A.; Svoboda, M.D. Drought Early Warning Systems in the Context of Drought Preparedness and Mitigation. Early Warning Systems for Drought Preparedness and Drought Management 2000, 1-21. Available online: https://www.preventionweb.net/publications/view/1882 (accessed on 2 March 2020).

4. Yao, N.; Li, L.; Feng, P.; Liu, D.L.; Liu, D.L.; Liu, Y.; Jiang, K.; Hu, X.; Li, Y. Projections of drought characteristics in China based on a standardized precipitation and evapotranspiration index and multiple GCMs. Sci. Total Environ. 2020, 704, 135245. [CrossRef] [PubMed]

5. Mathbout, S.; Lopez-Bustins, J.A.; Martin-Vide, J.; Bech, J.; Rodrigo, F.S. Spatial and temporal analysis of drought variability at several time scales in Syria during 1961-2012. Atmos. Res. 2018, 200, 153-168. [CrossRef]

6. Mishra, A.K.; Singh, V.P. A review of drought concepts. J. Hydrol. 2010, 391, 202-216. [CrossRef]

7. Rathore, M. State Level Analysis of Drought Policies and Impacts in Rajasthan, India; International Water Management Institute (IWMI): Colombo, Sri Lanka, 2004; Volume 93.

8. Rhee, J.; Im, J.; Carbone, G.J. Monitoring agricultural drought for arid and humid regions using multi-sensor remote sensing data. Remote. Sens. Environ. 2010, 114, 2875-2887. [CrossRef]

9. Wang, W.; Ertsen, M.W.; Svoboda, M.D.; Hafeez, M. Propagation of drought: From meteorological drought to agricultural and hydrological drought. Adv. Meteorol. 2016, 2016, 6547209. [CrossRef]

10. Huang, S.; Li, P.; Huang, Q.; Leng, G.; Hou, B.; Ma, L. The propagation from meteorological to hydrological drought and its potential influence factors. J. Hydrol. 2017, 547, 184-195. [CrossRef]

11. Li, S.; Yao, Z.; Liu, Z.; Wang, R.; Liu, M.; Adam, J.C. The spatio-temporal characteristics of drought across Tibet, China: Derived from meteorological and agricultural drought indexes. Theor. Appl. Clim. 2019, 137, 2409-2424. [CrossRef]

12. Stefan, S.; Ghioca, M.; Rimbu, N.; Boroneant, C. Study of meteorological and hydrological drought in southern Romania from observational data. Int. J. Clim. 2004, 24, 871-881. [CrossRef]

13. Wu, J.; Chen, X.; Yao, H.; Gao, L.; Chen, Y.; Liu, M. Non-linear relationship of hydrological drought responding to meteorological drought and impact of a large reservoir. J. Hydrol. 2017, 551, 495-507. [CrossRef]

14. Zargar, A.; Sadiq, R.; Naser, B.; Khan, F.I. A review of drought indices. Environ. Rev. 2011, 19, 333-349. [CrossRef]

15. Gidey, E.; Dikinya, O.; Sebego, R.; Segosebe, E.; Zenebe, A. Using drought indices to model the statistical relationships between meteorological and agricultural drought in Raya and its environs, Northern Ethiopia. Earth Syst. Environ. 2018, 2, 265-279. [CrossRef]

16. Ezzine, H.; Bouziane, A.; Ouazar, D. Seasonal comparisons of meteorological and agricultural drought indices in Morocco using open short time-series data. Int. J. Appl. Earth Obs. Geoinf. 2014, 26, 36-48. [CrossRef]

17. Vicente-Serrano, S.M.; Beguería, S.; López-Moreno, J.I. A multiscalar drought index sensitive to global warming: The standardized precipitation evapotranspiration index. J. Clim. 2010, 23, 1696-1718. [CrossRef]

18. Wu, J.; Miao, C.; Zheng, H.; Duan, Q.; Lei, X.; Li, H. Meteorological and hydrological drought on the Loess Plateau, China: Evolutionary characteristics, impact, and propagation. J. Geophys. Res. Atmos. 2018, 123, 11-569. [CrossRef]

19. Hisdal, H.; Tallaksen, L.M. Estimation of regional meteorological and hydrological drought characteristics: A case study for Denmark. J. Hydrol. 2003, 281, 230-247. [CrossRef]

20. Obled, C.; Creutin, J.D. Some developments in the use of empirical orthogonal functions for mapping meteorological fields. J. Clim. Appl. Meteorol. 1986, 25, 1189-1204. [CrossRef]

21. Wang, D.; Hejazi, M.; Cai, X.; Valocchi, A.J. Climate change impact on meteorological, agricultural, and hydrological drought in central Illinois. Water Resour. Res. 2011, 47, 1995-2021. [CrossRef]

22. Duan, K.; Mei, Y. Comparison of meteorological, hydrological and agricultural drought responses to climate change and uncertainty assessment. Water Resour. Manag. 2014, 28, 5039-5054. [CrossRef] 
23. Vicente-Serrano, S.M. Differences in spatial patterns of drought on different time scales: An analysis of the Iberian Peninsula. Water Resour. Manag. 2006, 20, 37-60. [CrossRef]

24. Pasho, E.; Camarero, J.J.; De Luis, M.; Vicente-Serrano, S.M. Impacts of drought at different time scales on forest growth across a wide climatic gradient in North-Eastern Spain. Agric. For. Meteorol. 2011, 151, 1800-1811. [CrossRef]

25. Xu, H.; Wang, X.-P.; Zhao, C.-Y.; Yang, X. Diverse responses of vegetation growth to meteorological drought across climate zones and land biomes in northern China from 1981 to 2014. Agric. For. Meteorol. 2018, 262, 1-13. [CrossRef]

26. Yao, N.; Li, Y.; Li, N.; Yang, D.; Ayantobo, O.O. Bias correction of precipitation data and its effects on aridity and drought assessment in china over 1961-2015. Sci. Total Environ. 2018, 639, 1015-1027. [CrossRef] [PubMed]

27. Zhao, S. A new scheme for comprehensive physical regionalization in China. Acta Geogr. Sin. 1983, 38, 1-10. (In Chinese)

28. Global Land Data Assimilation System. Available online: https://disc.gsfc.nasa.gov/datasets?Keywords= GLDAS/ (accessed on 15 July 2019).

29. Kumar, S.; Peters-Lidard, C.; Tian, Y.; Houser, P.; Geiger, J.; Olden, S.; Lighty, L.; Eastman, J.; Doty, B.; Dirmeyer, P. Land information system: An interoperable framework for high resolution land surface modeling. Environ. Model. Softw. 2006, 21, 1402-1415. [CrossRef]

30. Rodell, M.; Houser, P.R.; Jambor, U.; Gottschalck, J.; Mitchell, K.; Meng, C.-J.; Arsenault, K.; Cosgrove, B.; Radakovich, J.; Bosilovich, M.; et al. The global Land Data Assimilation System. Bull. Am. Meteorol. Soc. 2004, 85, 381-394. [CrossRef]

31. Niu, G.-Y.; Yang, Z.-L.; Dickinson, R.E.; Gulden, L.E.; Su, H. Development of a simple groundwater model for use in climate models and evaluation with Gravity Recovery and Climate Experiment data. J. Geophys. Res. Space Phys. 2007, 112. [CrossRef]

32. Syed, T.H.; Famiglietti, J.S.; Rodell, M.; Chen, J.; Wilson, C.R. Analysis of terrestrial water storage changes from GRACE and GLDAS. Water Resour. Res. 2008, 44, 472-486. [CrossRef]

33. Yang, T.; Wang, C.; Yu, Z.; Xu, F. Characterization of spatio-temporal patterns for various GRACE- and GLDAS-born estimates for changes of global terrestrial water storage. Glob. Planet. Chang. 2013, 109, 30-37. [CrossRef]

34. Lv, M.; Ma, Z.; Yuan, X.; Lv, M.; Li, M.; Zheng, Z. Water budget closure based on GRACE measurements and reconstructed evapotranspiration using GLDAS and water use data for two large densely-populated mid-latitude basins. J. Hydrol. 2017, 547, 585-599. [CrossRef]

35. Google Earth Engine. Available online: https://earthengine.google.com/ (accessed on 15 July 2019).

36. Li, L.; Yao, N.; Liu, D.L.; Song, S.; Lin, H.; Chen, X.; Liu, D.L. Historical and future projected frequency of extreme precipitation indicators using the optimized cumulative distribution functions in China. J. Hydrol. 2019, 579, 124170. [CrossRef]

37. Leng, G.; Tang, Q.; Rayburg, S. Climate change impacts on meteorological, agricultural and hydrological droughts in China. Glob. Planet. Chang. 2015, 126, 23-34. [CrossRef]

38. Zarch, M.A.A.; Sivakumar, B.; Sharma, A. Droughts in a warming climate: A global assessment of Standardized precipitation index (SPI) and Reconnaissance drought index (RDI). J. Hydrol. 2015, 526, 183-195. [CrossRef]

39. Ayantobo, O.O.; Li, Y.; Song, S. Copula-based trivariate drought frequency analysis approach in seven climatic sub-regions of mainland China over 1961-2013. Theor. Appl. Climatol. 2019, 137, 2217-2237. [CrossRef]

40. Mckee, T.; Doesken, N.; Kleist, J. The relationship of drought frequency and duration to time scales. In Proceedings of the 8th Conference on Applied Climatology, Anaheim, CA, USA, 17-22 January 1993; American Meteorological Society: Boston, MA, USA, 1993; pp. 179-183.

41. Lloyd-Hughes, B.; Saunders, M.A. A drought climatology for Europe. Int. J. Clim. 2002, 22, 1571-1592. [CrossRef]

42. Yao, N.; Feng, H.; Lei, T.; Peng, L. Drought evolution, severity and trends in mainland China over 1961-2013. Sci. Total Environ. 2018, 616-617, 73-89. [CrossRef] [PubMed]

43. Vicente-Serrano, S.M.; López-Moreno, J.I.; Beguería, S.; Lorenzo-Lacruz, J.; Azorin-Molina, C.; Morán-Tejeda, E. Accurate computation of a Streamflow Drought Index. J. Hydrol. Eng. 2012, 17, 318-332. [CrossRef] 
44. Hao, Z.; AghaKouchak, A.; Nakhjiri, N.; Farahmand, A. Global integrated drought monitoring and prediction system. Sci. Data 2014, 1, 140001. [CrossRef] [PubMed]

45. Shukla, S.; Wood, A.W. Use of a standardized runoff index for characterizing hydrologic drought. Geophys. Res. Lett. 2008, 35, 02405. [CrossRef]

46. Ding, Y. Chinese Meteorological Disasters Pandect; China Meteorological Press: Beijing, China, 2008. (In Chinese)

47. Kendall, M.G. Rank Correlation Methods; Griffin: London, UK, 1975.

48. Mann, H.B. Nonparametric tests against trend. Econometrica 1945, 13, 245-259. [CrossRef]

49. Hamed, K.H.; Rao, A.R. A modified Mann-Kendall trend test for autocorrelated data. J. Hydrol. 1998, 204, 182-196. [CrossRef]

50. Liu, D.L.; Horton, R.; Ren, T.; Chen, C. Prediction of annual reference evapotranspiration using climatic data. Agric. Water Manag. 2010, 97, 300-308. [CrossRef]

51. Topaloğlu, F. Regional trend detection of Turkish river flows. Hydrol. Res. 2006, 37, 165-182. [CrossRef]

52. Liu, D.L.; Yao, N.; Chau, H.W. Influences of removing linear and nonlinear trends from climatic variables on temporal variations of annual reference crop evapotranspiration in Xinjiang, China. Sci. Total Environ. 2017, 592, 680-692. [CrossRef] [PubMed]

53. Shiru, M.S.; Shahid, S.; Chung, E.S.; Alias, N. Changing characteristics of meteorological droughts in Nigeria during 1901-2010. Atmos. Res. 2019, 223, 60-73. [CrossRef]

54. Whitcher, B.; Guttorp, P.; Percival, D.B. Wavelet analysis of covariance with application to atmospheric time series. J. Geophys. Res. Space Phys. 2000, 105, 14941-14962. [CrossRef]

55. Biswas, A.; Si, B.C. Application of continuous wavelet transform in examining soil spatial variation: A review. Math. Geol. 2011, 43, 379-396. [CrossRef]

56. Li, L.; Yao, N.; Li, Y.; Liu, D.L.; Wang, B.; Ayantobo, O.O. Future projections of extreme temperature events in different sub-regions of China. Atmos. Res. 2019, 217, 150-164. [CrossRef]

57. Biswas, A. Scale-location specific soil spatial variability: A comparison of continuous wavelet transform and Hilbert-Huang transform. Catena 2018, 160, 24-31. [CrossRef]

58. Ren, J.; Liu, H.; Yin, Y.; He, S. Drivers of greening trend across vertically distributed biomes in temperate arid Asia. Geophys. Res. Lett. 2007, 34, 07707. [CrossRef]

59. Xu, G.; Zhang, H.; Chen, B.; Zhang, H.; Innes, J.; Wang, G.; Yan, J.; Zheng, Y.; Zhu, Z.; Myneni, R.B. Changes in vegetation growth dynamics and relations with climate over China's landmass from 1982 to 2011. Remote Sens. 2014, 6, 3263-3283. [CrossRef]

60. Wen, Z.; Wu, S.; Chen, J.; Lü, M. NDVI indicated long-term interannual changes in vegetation activities and their responses to climatic and anthropogenic factors in the Three Gorges Reservoir Region, China. Sci. Total Environ. 2017, 574, 947-959. [CrossRef] [PubMed]

61. Zhang, Y.J.; Wang, C.Y.; Zhang, J.Q. Analysis of the spatial and temporal characteristics of drought in the north china plain based on standardized precipitation evapotranspiration index. Acta Ecol. Sin. 2015, 35, 7098-7107. (In Chinese)

62. Ma, Z. Interannual characteristics of the surface hydrological variables over the arid and semi-arid areas of northern China. Glob. Planet. Chang. 2003, 37, 189-200. [CrossRef]

63. Zhang, J.; Mu, Q.; Huang, J. Assessing the remotely sensed Drought Severity Index for agricultural drought monitoring and impact analysis in North China. Ecol. Indic. 2016, 63, 296-309. [CrossRef]

64. Xu, K.; Yang, D.; Xu, X.; Lei, H. Copula based drought frequency analysis considering the spatio-temporal variability in Southwest China. J. Hydrol. 2015, 527, 630-640. [CrossRef]

65. Sun, G.; Li, Z.; Feng, J. Relationship between atmospheric low-frequency oscillation and two severe drought events in southwest china. Plateau Meteorol. 2014, 33, 1562-1567. (In Chinese)

66. Klamt, A.-M.; Hu, K.; Huang, L.; Chen, X.; Liu, X.; Chen, G. An extreme drought event homogenises the diatom composition of two shallow lakes in southwest China. Ecol. Indic. 2020, 108, 105662. [CrossRef]

67. Vu, M.T.; Raghavan, V.S.; Liong, S.-Y. Ensemble climate projection for hydro-meteorological drought over a river basin in Central Highland, Vietnam. KSCE J. Civ. Eng. 2015, 19, 427-433. [CrossRef]

68. Wilhite, D.A.; Glantz, M.H. Understanding: The drought phenomenon: The role of definitions. Water Int. 1985, 10, 111-120. [CrossRef]

69. Sun, Z.; Zhu, X.; Pan, Y.; Zhang, J.; Liu, X. Drought evaluation using the GRACE terrestrial water storage deficit over the Yangtze River Basin, China. Sci. Total Environ. 2018, 634, 727-738. [CrossRef] [PubMed] 
70. Lai, C.; Zhong, R.; Wang, Z.; Wu, X.; Chen, X.; Wang, P.; Lian, Y. Monitoring hydrological drought using long-term satellite-based precipitation data. Sci. Total Environ. 2019, 649, 1198-1208. [CrossRef] [PubMed]

71. Ma'Rufah, U.; Hidayat, R.; Prasasti, I. Analysis of relationship between meteorological and agricultural drought using standardized precipitation index and vegetation health index. IOP Conf. Ser. Earth Environ. Sci. 2017, 54, 12008. [CrossRef]

72. Jiang, Y.; Zhang, X.; Yang, L.; He, C. Analysis and comparison of spatial and temporal patterns of meteorological and hydrological drought indices in the upper reach of the Heihe river watershed, northwest china. Resour. Sci. 2014, 36, 1842-1851. (In Chinese)

73. Li, Y.; He, J.; Li, X. Evolution analysis of meteorological and hydrological drought in Yunnan Red River Basin based on SPEI and SDI index. Prog. Geogr. 2016, 35, 758-767. (In Chinese)

74. Fu, B. On the calculation of evaporation from land surface in mountainous areas. Sci. Meteorol. Sin. 1996, 5, 24-30. (In Chinese)

75. Ma, Q.; Li, Y.; Feng, H.; Yu, Q.; Zou, Y.; Liu, F.; Pulatov, B. Performance evaluation and correction of precipitation data using the 20-year IMERG and TMPA precipitation products in diverse subregions of China. Atmos. Res. 2020, in press. [CrossRef]

Publisher's Note: MDPI stays neutral with regard to jurisdictional claims in published maps and institutional affiliations.

(C) 2020 by the authors. Licensee MDPI, Basel, Switzerland. This article is an open access article distributed under the terms and conditions of the Creative Commons Attribution (CC BY) license (http://creativecommons.org/licenses/by/4.0/). 